\title{
Endothelial Cells Guided by Immobilized Gradients of Vascular Endothelial Growth Factor on Porous Collagen Scaffolds
}

By

Devangbhai Odedra

A thesis submitted in conformity with the requirements

for the degree of Master's of Applied Science

Department of Chemical Engineering and Applied Chemistry

University of Toronto

(C) Copyright by Devangbhai Odedra 2011 


\title{
Endothelial Cells Guided by Immobilized Gradients of Vascular Endothelial Growth Factor on Porous Collagen Scaffolds
}

\author{
Devangbhai Odedra \\ Master's of Applied Science \\ Department of Chemical Engineering and Applied Chemistry \\ University of Toronto
}

2011

\begin{abstract}
A key challenge in tissue engineering is overcoming cell death in the scaffold interior due to the limited diffusion of oxygen and nutrients therein. We hypothesized here that immobilizing a gradient of vascular endothelial growth factor (VEGF-165) would guide endothelial cells into the interior of the scaffold thereby enhancing angiogenesis. The protein was immobilized onto a collagen scaffold through carbodiimide chemistry by one of the three methods experimented: placing $5 \mu \mathrm{l}$ of the solution at the center of the scaffold to create a $\sim 2 \mathrm{ng} / \mathrm{ml} / \mathrm{mm}$ gradient in a radial direction. D4T endothelial cells were observed to be guided by this VEGF-165 gradient deep into the center of the scaffold compared to both uniformly immobilized VEGF-165 and VEGFfree controls. We concluded that the VEGF-165 gradient scaffolds promoted the migration, and not proliferation, of cells deep into the scaffold. These gradient scaffolds provide the foundation for future in vivo tissue engineering studies.
\end{abstract}




\section{Acknowledgements}

First and foremost, I would like to thank my thesis advisors, Dr. Milica Radisic and Dr. Molly Shoichet, for their indispensable guidance during my project. I am very grateful for their cooperation with my transition plans between graduate school and work. I would also like to acknowledge the thesis committee members - Professor Edgar Acosta and Professor Julie Audet.

I thank every person in the Radisic lab. Loraine Chiu and Rohin Iyer deserve special mention for their continued guidance and support. Thanks also to Larry Ming for keeping autoclaved tools at my disposal whenever needed!

I also thank every person in the Shoichet lab. Thanks to Dr. Douglas Baumann for helpful discussions, Dr. Mike Cooke for support with instruments and Yukie Aizawa for mentorship about VEGF!

I would like to thank my family for their love and support. My roommate Neil Sheth deserves special mention for being the most cooperative roommate ever! My sincere appreciation also goes to my friends at UofT for their social support.

Finally, this thesis work was financially supported by a grant from Ontario Centres of Excellence, Ontario Graduate Scholarship in Sciences and Technology and University of Toronto Open Fellowship. 


\section{Table of Contents}

\section{Contents}

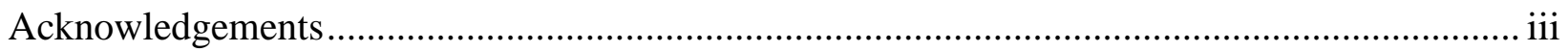

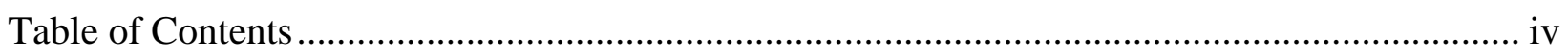

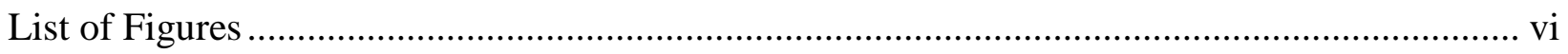

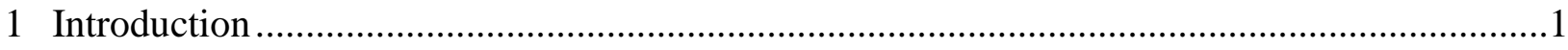

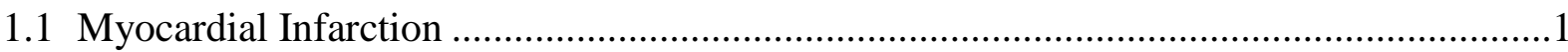

1.2 Cardiac Tissue Engineering …………………..............................................................

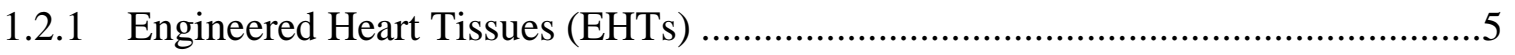

1.2.2 Vascularization Challenge …………………….............................................

1.2.3 Biomimetic Cell Seeding and Culture Techniques ..............................................

1.2.4 Growth Factor Delivery ..............................................................................

1.3 Vascular Endothelial Growth Factor ........................................................................11

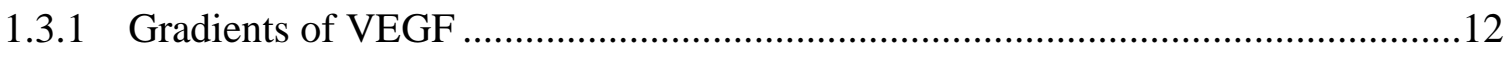

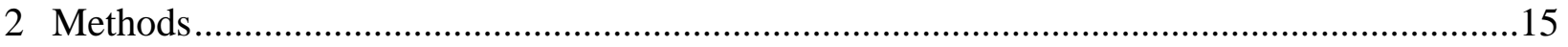

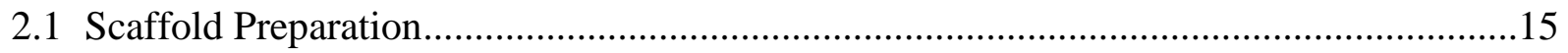

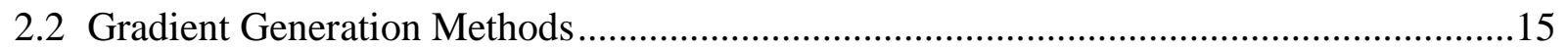

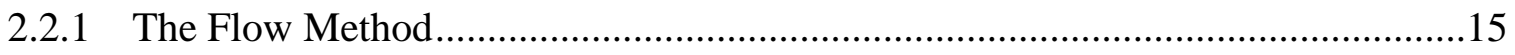

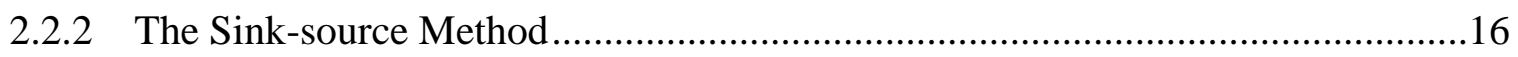

2.2.3 Point-source Method......................................................................................19

2.3 Concentration Profile Characterization..........................................................................20

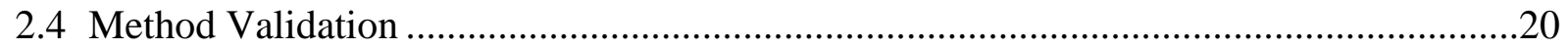

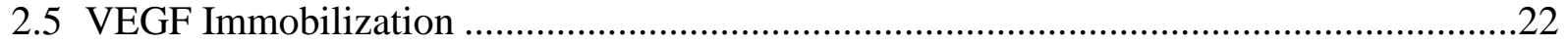

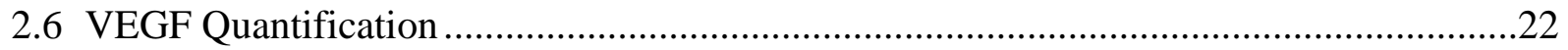




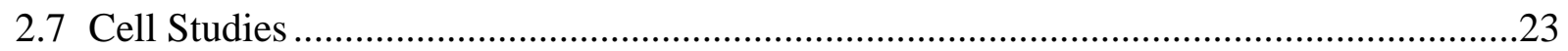

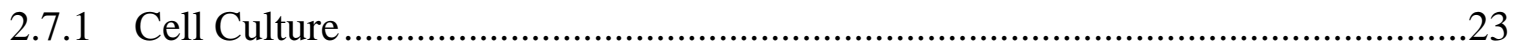

2.7.2 Cell Migration Study...................................................................................24

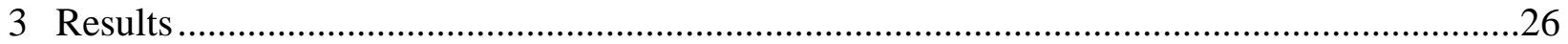

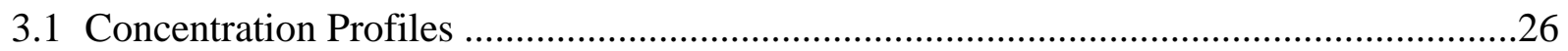

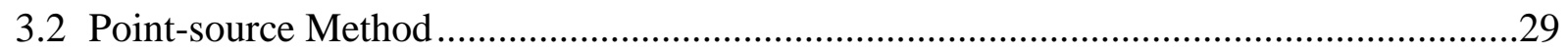

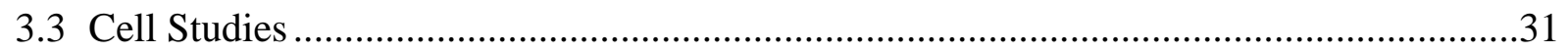

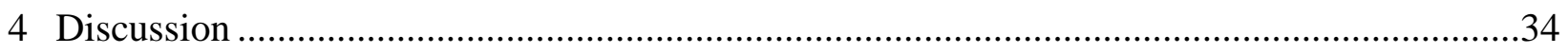

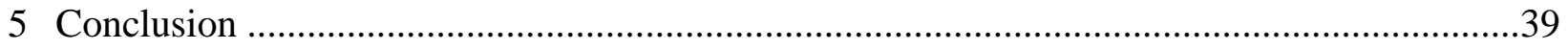

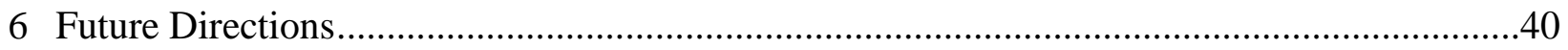

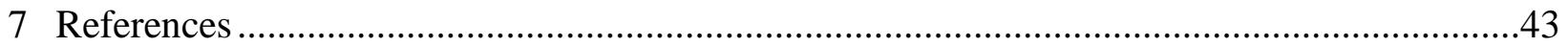

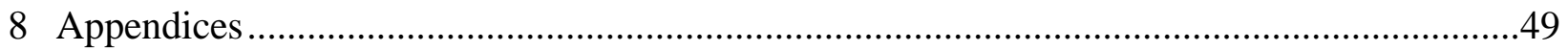




\section{List of Figures}

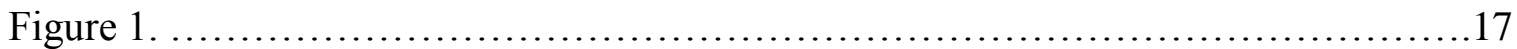

Overview of the gradient generation methods.

Figure 2.

.27

Fluorescence Intensity Profiles of Alexa-594 BSA for the Three Gradient Generation Methods.

Figure 3. 28

The Sink-source method suffers from lack of reproducibility and uneven VEGF distribution.

Figure 4.

Protein quantification for the Point-source method.

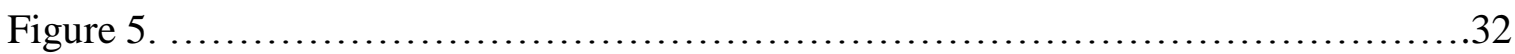

Scaffolds with gradients lead to a more centralized cell distribution.

Supplementary Figure 1.

Type IA collagenase was chosen for scaffold digestion.

Supplementary Figure 2.

Cell density of 5000 per scaffold was chosen.

Supplementary Figure 3.

Overview of the Cell Seeding Methods.

Supplementary Figure 4.

Cell distribution varied for different seeding methods. 


\section{Chapter 1 \\ Introduction}

\section{Introduction}

\subsection{Myocardial Infarction}

Heart is perhaps the most important vital organ in the human body. Beating at about 86,000 beats per day, this organ keeps the blood flowing in the human body. Any serious abnormality to the heart, such as the congenital heart disease in the newborns that affects every 14 out of 1000 newborns, often results in serious complications or fatality [1].

In adults, myocardial infarction (MI) accounts for nearly $40 \%$ of all deaths occurring in the United States. It is also the leading cause of death worldwide [1]. Hence, it is of utmost clinical attention for the researchers and clinicians worldwide.

Heart tissue is comprised of a highly organized tissue that consists of primarily three cell types: cardiomyocytes (the cells responsible for beating of the heart), endothelial cells (the cells responsible for creating vascularization within the heart) and fibroblasts (the supporting cells that secrete extracellular matrix required by other cells). Cardiomyocytes are aligned in parallel arrays and connected by gap junctions. The specialized pacemaker cells in the heart generate an electrical signal that travels through the gap junctions, causing influx of calcium ions into the cell cytoplasm, and causing a harmonized beating of the heart [2].

Heart cells are supplied by a rich network of capillaries, with capillaries spaced at every $20 \mu \mathrm{m}$. These cells are highly metabolic, requiring plenty of oxygen supply [3]. In 
MI, a blood vessel supplying a certain part of the heart becomes chronically clogged with plaque, up to a point when the cells in the affected region stop receiving adequate supply of oxygen. This causes cells in this region to start dying. Over time, a non-contractile fibrous scar tissue, rich in collagen, replaces the once healthy myocardium. The inability of this scar tissue to conduct electrical wavefronts reduces the heart's functional efficiency. This affects the normal heart function and consequently, the heart has to work harder, resulting in further deterioration of the heart such as ventricular thinning. Other organs in the body are also affected by the compromised blood supply. At some point in the progression of the disease, the heart reaches a stage where it is not able to keep up with the demands of the body and consequently, a heart attack occurs [4] .

Heart cells are terminally differentiated - they cannot divide or proliferate. Hence, there is no possibility of a natural regeneration of the tissue. Several pharmacologic agents are available to either delay or reduce the progression of the heart failure. However, they are not meant to cure or improve the condition. Another therapeutic option available for the MI patients is left ventricular assist devices (VADs). VADs are aimed at preventing remodelling and dilation of the left ventricle via unloading the dilated chamber. There are also mechanical alternatives for advanced heart failure: reverse remodelling strategies using either biventricular pacemakers where electrical dyssynchrony is present or external constraining mesh 'jackets' wrapped around the failing heart to prevent ongoing ventricular dilatation [2]. However, researchers have reported mixed reviews and the advantage of these alternatives are not well-established [5]. Whole organ heart-transplants are another alternative, but this option is highly limited by the scarce availability of organ donators. 


\subsection{Cardiac Tissue Engineering}

The term "Tissue Engineering" was first coined at the Lake Tahoe conference held by the National Science Foundation in 1988. It is originally defined as "the application of principles and methods of engineering and life sciences toward fundamental understanding of structure-function relationships in normal and pathological mammalian tissues and the development of biological substitutes to restore, maintain, or improve tissue function. [6]" The field of tissue engineering has undergone a phenomenal boost around the world in recent times with publications rates escalating from mere few to thousands per year.

In line with the definition of tissue engineering above, Cardiac Tissue Engineering aims to restore the function of a damaged heart, with efforts aimed mostly at heart valve and myocardial tissue engineering. In myocardial tissue engineering, there are basically two schools of thought in this research that both aim to achieve the same end result, regeneration of the damaged heart: cell injection and engineered heart tissue.

Although the two approaches are quite different in their mechanisms, they share the same set of variables that transcend the universal field of tissue engineering: cell source, biomaterial and signaling molecules. Several cell sources have been identified and investigated for the purpose of cardiac regeneration. Some of the extensively investigated cell types include bone marrow-derives adult stem cells $[7,8]$ and embryonic stem cells [9-11]. Some of the other cell types that carry some doubts in terms of their capability for the purpose of myocardial regeneration are the adipose-derived adult stem cells $[12,13]$ and the adult skeletal myoblasts [14]. Two recently explored area of cell source are the resident cardiac progenitor cells and induced pluripotent stem cells (iPS). 
Although heart cells are traditionally believed to be terminally differentiated, several groups have recently claimed to have isolated progenitor cells from the heart that have a potential of differentiating into cardiomyocytes and vascular cells $[15,16]$. iPS is an emerging technology where a set of transcriptional factors is introduced via a viral vector into somatic cells such as skin fibroblasts to "induce" pluripotency into them. This technology ideally enables the conversion of terminally differentiated cells into embryonic-stem-like cells that can be differentiated into the desired progeny of cells [17, 18]. Work is currently underway into exploring the differentiation potential of these cells into myocardial lineage. Similarly, a myriad of biomaterials, either synthetic or natural, have been investigated. Synthetic polymers include polyesters (ex. polylactic acid and polyglycolic acid) and elastomeric polymers (ex. polyurethane polyethylene glycol) and natural polymers include extracellular derivatives (collagen, Matrigel®, glycosaminoglycans), alginate and fibrin glue [2]. Since the behavior of cells in vivo is primarily dictated by the biochemical molecules in the body, such as hormones and growth factors, it is logical to enhance the regenerative strategy by supplementing it with relevant bioactive molecules. These molecules have different effects, such as promoting proliferation, migration or differentiation. For example, RGD is a commonly used peptide that is incorporated in biomaterials to promote cell attachment through the cell-surface integrins [19].

The main concept behind using cell injection is that if cells of regenerative capacity are delivered at the injured site, then they can integrate with the host tissue over time and re-establish the lost tissue. Studies have focused on either delivering the cells in cell suspension or injecting cells along with a flexible biomaterial, such as a hydrogel, 
which would assume the shape of the defect and provide the cells a protective as well as proliferative environment while they are integrated into the host tissue [20].

Both the cell injection and EHT carry a potential to be successful at this point. The main disadvantages of cell injection are immediate cell death and a small cell survival rate beyond 24 hours upon injection into the heart since they are exposed to a hostile environment in short duration [21]. In light of the study in question, the focus will be only on EHTs.

\subsubsection{Engineered Heart Tissues (EHTs)}

The ultimate goal of the EHTs is to use a combination of cells, scaffolds and growth factors to design artificial tissue constructs that can mimic the native heart tissue. These constructs can either replace the infracted area of the heart or be placed on top of the infracted area. Although, the former is the ideal hope, the current state of research hopes to achieve the latter. Implanting the construct on top of the infracted region would add a level of functionality to that region and either improve the overall heart function or prevent it from degrading any further [20].

The EHTs reported to date can broadly be divided into three categories: (i) cellsheet engineered (ii) mechanically stimulated (iii) electrically stimulated.

Shimizu, Okano and colleagues have pioneered the tissue engineering approach of stacking cell sheets. Isolated neonatal rat ventricular myocytes are first plated on surfaces of thermo-responsive polymer poly(N-isopropylacylamide). This polymer is hydrophobic and cell-adhesive at the physiological temperature $\left(37^{\circ} \mathrm{C}\right)$ and turns hydrophilic and non- 
cell adhesive at lower temperatures (below $32^{\circ} \mathrm{C}$ ). Once the cells have reached confluence and established cell-cell contacts, the sheets can be detached from the surface without disturbing the gap junction between the cells or the cell-surface proteins, which would normally happen during a trypsin-mediated detachment. The sheets can be stacked to create 3-D constructs. The constructs have been tested in animal models by subcutaneous implantation of two or four layer thick cell sheet stacks into 3- and 8-week old male F344 nude rats. Some improvement was observed in the mechanical strength for the four-layer sheet in 3-week old rats [22, 23].

Eschenhagen and Zimmermann have established a different approach where the constructs are stimulated with mechanical stretching to induce the assembly of the cardiomyocytes into native-like striated patterns. Neonatal rat heart cells are cultivated in a mixture of collagen gel, Matrigel ${ }^{\circledR}$ and later on growth factors and subjected to unidirectional and cyclic mechanical stetch at $10 \%$ strain and $2 \mathrm{~Hz}$. Under these conditions, the cells formed highly differentiated cardiac muscle synctium that exhibited contractile and electrophysiological properties of working myocardium [24]. Multiple circular strips of constructs were combined to form a large-scale implantable tissue patch. In an immunosuppressed rat model, the constructs were evaluated four-weeks postimplantation for the functional improvement. Pacing of the implanted constructs led to propagation of electrical responses, unlike in the sham groups as well as groups implanted with a non-contractile formaldehyde-treated constructs. In addition, the authors observed conduction velocity and anisotropy in the implanted constructs similar to the native tissue. The constructs appeared to delay the ventricular thinning and led to a reduced increase in the diastolic volume and pressure compared to the sham groups [25]. The constructs were 
about $\sim 400 \mu \mathrm{m}$ thick and showed vessel formation by the donor cells that supported the construct beyond the $100 \mu \mathrm{m}$ mark of diffusion limit [26].

Radisic's group has pioneered yet another approach to designing native-like heart tissues - that of electrical stimulation. Cardiac constructs were prepared by seeding neonatal rat cardiomyocytes in Matrigel ${ }^{\circledR}$ onto collagen sponges and culturing for 3 days. They were then subjected to trains of electrical pulses of $5 \mathrm{~V} / \mathrm{cm}, 1 \mathrm{~Hz}$ and $2 \mathrm{~ms}$ duration. Electrical stimulation led to a more organized morphology of the constructs [27]. On a molecular level, electrical stimulation increased the expression of myosin heavy chain, Cx-43, creatine kinase-MM, and cardiac troponin-I [27].

\subsubsection{Vascularization Challenge}

An intrinsic problem of the previously reported EHTs is that they mainly rely on diffusion for oxygen transport to the cells seeded on the constructs. Heart is a highly dense tissue, with a cell density of $\sim 10^{8}$ cells $/ \mathrm{cm}^{3}$, and due to the nature of the physiological function, the cells require abundant supplies of oxygen and nutrients, which diffusion is not able to deliver as it is limited to distances of about 100-200 $\mu \mathrm{m}$ [28]. This results in significant cell death towards the center of the scaffold and compromises the functionality of the construct as a whole. A clinically relevant patch thickness is on the order of several millimeters but diffusion limit is on the order of 100-200 $\mu \mathrm{m}$. Hence, this gap in the scale needs to be addressed. Several strategies have been investigated for this purpose. They can be broadly divided into two categories: (i) biomimetic cell seeding and culturing techniques and (ii) use of growth factors. 


\subsubsection{Biomimetic Cell Seeding and Culture Techniques}

Several flow-based strategies have been investigated in order to overcome the diffusion limitation. Some of the fundamental strategies include using spinner flasks, rotating bioreactors and orbital shakers for the cultivation of the constructs. However, the flow of the culture medium within the constructs still remains limited by diffusion.

Kofidis et. al. supplied a pulsatile flow of the medium around cardiomyocytes encapsulated in fibrin glue around a rat artery [29]. Dvir et. al. designed a perfusion bioreactor by placing a mesh that streamlines the medium flow into a homogeneous flow and enhances its contact with the construct placed downstream from the mesh. Improved cell viability was observed $[30,31]$. Our lab has designed a similar bioreactor that mimics the in vivo-like convective-diffusive oxygen transport, by providing a pulsatile flow through a cultured construct in a bio-reactor [28, 32]. Cells are seeded on porous collagen scaffolds containing interconnected network of channels, which enhance diffusion and also act as a precursor to blood vessel development, and cultured in the bio-reactor. In addition, this system has also been used to achieve a more uniform cell-seeding density within the construct [33]. Further enhancement in the oxygen delivery was achieved by supplementing the culture medium with an oxygen carrier [34, 35]. Both the perfusion and the oxygen carrier improved the viability and enabled the formation of compact layers of viable cells around the channels.

\subsubsection{Growth Factor Delivery}

While the Biomimetic techniques aim to utilize the enhanced transport of culture medium to the cells to improve their survival and proliferation, cell death still occurs 
within the scaffolds upon implantation once these external factors are no longer present. Most of the cell death occurs within 3-7 days post-implantation [36] during which time the native blood vessels grow into the construct. To overcome the problem of cell death, an ideal strategy would include pre-forming the vascular-like structures within the construct as has been reported [37] [38, 39] [40] and a mechanism to guide the infiltration of the host vasculature into the construct upon implantation. One strategy is to induce vascularization by utilizing the cells' internal signals and mechanism to develop new vessels. This is done by providing the cells biomolecular cues that are normally found in native environment. Growth factors play a major role in the development and regulation of structures and functions from a very early embryonic stage. Hence, they are an attractive tool in tissue engineering for promoting or enhancing biological effects.

\subsubsection{Growth Factor Incorporation by Delivery}

Growth factors have been delivered to the cells on the scaffold by gene delivery, soluble delivery or controlled release. Vascular Endothelial Growth Factor (VEGF) and Angiopoietin-1 (Ang-1) have been delivered by adenovirus-mediated gene transfer into the adjacent fat pad of the rat mesentery and functionally active microvasculature was evaluated in response to the growth factors in combination or separately [41]. Culture media supplemented with growth factors have also been investigated for their potential to promote vascularization in animal models [42]. Several studies have focused on a controlled delivery of growth factors over a longer duration of time in order to simulate the natural sequestration of growth factors in native body. VEGF and Ang-1 were delivered in a hydrogel to elicit vascular maturity in rat aortic rings [43]. Mooney and 
colleagues have devised several strategies to deliver multiple growth factors through controlled release either by incorporating the growth factors directly or seeding endothelial cells into polymeric scaffolds that in turn release the growth factors in a controlled fashion.

\subsubsection{Growth Factor Immobilization}

While delivery of soluble growth factors through different mediums provides the biomolecular cues to the cells, a more prolonged and effective response can be achieved by covalently immobilizing the growth factor onto the biomaterial. Immobilization of biomolecular cues, such as growth factors onto tissue engineering scaffolds, has been investigated in several studies [44, 45]. Immobilized growth factors provide localized and prolonged cell stimulation because their rate of internalization is reduced and they have a longer half-life [46, 47]. Pro-angiogenic growth factors have been immobilized on biomaterials to enhance vascularization within the construct. Sahni and colleagues observed that surface-immobilized fibroblast growth factor - 2 (FGF-2) stimulated growth and enhanced the proliferative capacity of endothelial cells [48]. Another example of growth factor immobilization is to provide differentiation cues to stem-cells. This offers spatial control over the differentiation profile of the cells, as recently shown by the site-specific differentiation of embryonic stem cells into vascular or smooth muscle cells based on the immobilization profile of a growth factor [49]. 


\subsection{Vascular Endothelial Growth Factor}

Vascular Endothelial Growth Factor (VEGF) plays a key role in the process of angiogenesis by mediating endothelial cell proliferation, migration and tube formation. Although a family of VEGF isoforms from VEGF-A to VEGF-E exists, VEGF-A $\left(\mathrm{VEGF}_{165}\right.$, now on referred to as VEGF) is the most prevalent. Two receptor tyrosine kinases, VEGFR-1 (flt-1) and VEGFR2 (KDR/flk-1), have been identified on ECs that participate in the VEGF signaling pathway. Flt-1 is believed to play a role in EC proliferation and Flk-1 in differentiation and vascular organization [50]. Binding of VEGF to the receptors leads to receptor dimerization and autophosphorylation, which leads to a downstream pathway involving recruitment of signaling proteins containing srchomology-2 domains to the phosphorylated tyrosines [51].

Because of its importance in the angiogensis, VEGF has received wide attention for tissue engineering purposes. More specifically, its immobilization on biomaterials has been explored in several previous studies. Shen et. al. observed increased endothelial cell number and infiltration on collagen scaffolds uniformly immobilized with VEGF [52]. Upon implantation of scaffolds with uniformly immobilized VEGF-165 into right ventricular wall defects in rat hearts, enhanced angiogenesis and patch stability was observed compared to VEGF-free controls [53]. We also uniformly immobilized VEGF165 in combination with Angiopoetin-1 onto collagen scaffolds. Increased cell density and proliferation was observed on co-immobilized scaffolds vs. the controls without growth factors in vitro, and the increased vessel density was observed in the coimmobilized scaffolds implanted onto chicken chorio-allantoic membrane (CAM) [54]. Koch et. al. immobilized a modified VEGF onto collagen matrices and observed a small but significant effect of immobilized VEGF by studying the angiogenic potential of the 
matrices in a CAM assay [55]. Taguchi et. al. co-immobilized VEGF with fibronectin onto a poly(acrylic acid) grafted polyethylene films using a water-soluble carbodiimide chemistry and observed increased cell growth promotion activity on cultured human umbilical vein endothelial cells [56].

\subsubsection{Gradients of VEGF}

Gradients of growth factors are known to induce chemotactic cell migration, such as the use of VEGF gradients to guide endothelial cells. Endothelial cell migration is an essential component in the process of angiogenesis and is mediated by VEGF gradients [57]. Most of the attempts at investigating VEGF gradients have been carried out in microfluidic devices at a micrometer scale, with the primary aim being to screen the chemotactic ability of a particular growth factor/cell type pair [58, 59]. Shamloo et. al. established a soluble VEGF gradient in a microfluidics channel and observed the migration of human umbilical vein endothelial cells from one side of the channel (low VEGF) to the other (high VEGF) over time period of several hours [58]. Chung et. al. established a soluble VEGF gradient along a microfluidic channel and observed the migration of human dermal microvascular endothelial cells (HMVEC) along the gradient in a collagen gel [59]. The potential of an immobilized VEGF gradient was recently proven by studying the migration of human microvascular endothelial cell filopodia in a 3D agarose hydrogel. The constructs with an immobilized gradient of VEGF, created using two-photon laser-guided chemistry, exhibited a deeper infiltration of filopodia compared to the uniform and blank controls [60]. 
Here we examine endothelial cell migration in a porous collagen scaffold containing a VEGF-165 gradient. Since porous or fibrous scaffolds are generally translucent or opaque, previous methods to generate gradients, such as laser-guided photon chemistry [60], cannot be used for the generation of $\mu \mathrm{m}$-mm scale gradients of immobilized growth factors. Thus, alternative approaches are required. Methods to generate growth factor gradients concurrently with the fabrication of porous scaffolds are available. For example, dye loaded Poly(D,L-lactide-co-glycolide) (PLG) microparticles were assembled into multilayered or gradient scaffolds by ethanol treatment, where the concentration of the released molecule can be spatially controlled within the scaffold [61]. Gradients of soluble BMP-4 and IGF-1 were created over $30 \mathrm{~mm}$ length scales by incorporating protein loaded silk microspheres into fibrous silk scaffolds [62]. Gradient makers were also utilized to generate gradients of nerve growth factor and neurotrophin-3 during polymerization and fabrication of poly(2-hydroxyethylmethacrylate)/poly(Llysine) scaffolds [63].

The goals of the study are to: 1) Develop a method to immobilize growth factor concentration gradients in a non-transparent porous scaffold; and 2) Demonstrate cell migration on the scaffold and in response to this gradient. To this end, we tested three methods to create gradients in the collagen scaffolds and then chose the best one to generate immobilized VEGF gradients using water-soluble chemistry. We analyzed the effect of the gradient on endothelial cell distribution in the collagen scaffolds. Ultimately, we aim to take advantage of the synergistic effects of both cell migration and proliferation on a VEGF gradient-containing scaffold as a means to promote host tissue integration by guiding host endothelial and other cells into the scaffold, as a step closer to inducing a vascular system. 


\section{Hypothesis}

Scaffolds with immobilized gradient of VEGF-165 are capable of directing endothelial cell migration compared to scaffolds with uniformly immobilized VEGF165 or no VEGF-165.

\section{Objectives}

1) Develop a method to immobilize VEGF-165 concentration gradients in a nontransparent pre-formed porous scaffold

2) Demonstrate endothelial cell migration on the scaffold in response to this gradient 


\section{Chapter 2 \\ Methods}

\section{Methods}

\subsection{Scaffold Preparation}

An FDA-approved collagen scaffold was used for this project (Ultrafoam collagen sponge, Davol, 1050050). This is a highly porous collagen sponge with pore size ranging between 100-200 $\mu \mathrm{m}$ [52]. The sterile sheet of the scaffold was cut into the desired shape, circle or rectangle, with either a circular autoclaved metal cork borer or autoclaved metal scissors, respectively. The diameter of the dry scaffold discs used throughout this project was $12 \mathrm{~mm}$, except that for the study to choose the correct digestive enzyme for the scaffold where the diameter was $7 \mathrm{~mm}$. The dimensions of the square scaffolds were 5 $\mathrm{mm} \times 6 \mathrm{~mm}$.

\subsection{Gradient Generation Methods}

\subsubsection{The Flow Method}

The apparatus for the Flow Method is shown in Fig. 1a. It consists of two $5 \mathrm{ml}$ syringes (BD, 309603) connected through a $5 \mathrm{~mm}$ diameter tygon tubing using two 3-way valves. In between the valves, a polycarbonate bioreactor used in previous cardiac tissue engineering studies [28, 33] (Apollo) was connected. In the bio-reactor, a circular collagen scaffold of $12 \mathrm{~mm}$ diameter was placed tightly between two metal meshes and silicone O-rings. Two $1 \mathrm{ml}$ syringes (BD, 309628) were connected to the 3 -way valves in order to remove any bubbles from the circuit. 
After mounting the circular scaffold in the bio-reactor, the $5 \mathrm{ml}$ syringe at the top end of the bioreactor was filled with PBS. The PBS was slowly injected out of the syringe through the circuit into the other syringe. This wets the scaffold with PBS. Once the entire circuit was filled with PBS, the three way valve at the top end of the bioreactor was closed to the $5 \mathrm{ml}$ syringe and opened to the $1 \mathrm{ml}$ syringe filled with the solution of interest. The solution was slowly $(\sim 100 \mu \mathrm{l}$ in 5 seconds) injected out of the syringe such that it flows through the 3-way valve and through the center of the stream and the collagen scaffold. The circuit was then drained through the $5 \mathrm{ml}$ syringe at the bottom of the bioreactor. The scaffold was taken out of the bio-reactor and rinsed in PBS to remove the excess solution of interest.

\subsubsection{The Sink-source Method}

In this method, the scaffold was mounted between two reservoirs as shown in Fig. 1 b. The dimensions of the scaffold mount and the scaffold were $5 \mathrm{~mm}$ x $6 \mathrm{~mm}$. The device was engraved on a $5 \mathrm{~mm}$ thick polycarbonate sheet (McMaster Carr) using a counter-top milling machine (Roland, Modela 3D Plotter MDX-15) equipped with a 1/32 inch tip drill bit (Roland, EMF-125-3F-031). Virtual Modela software was used to align the drill bit with the polycarbonate sheet surface. Then, DoctorEngrave was used to engrave the design into a depth of $1.5 \mathrm{~mm}$ (scaffold platform) and $2 \mathrm{~mm}$ (reservoirs), resulting in the device shown in Fig. $\mathbf{1 b}$.

The scaffold was first immersed in $250 \mu \mathrm{l}$ of PBS in a 96-well plate for 10 minutes. The platform on the device was coated with a thin layer of vacuum grease to form a sealant. After 10 minutes, the scaffold was dabbed on a Kim wipe to remove excess liquid and 
transferred to the platform on the device. A glass cover slide was cut into a square piece of $3 \mathrm{~cm}$ by $3 \mathrm{~cm}$ that would fit on top of the scaffold and act to hold it in place from above. The surface of the glass slide in contact with the scaffold was also coated with vacuum grease in order to prevent the leakage of solutions. The slide was then placed on top of the scaffold and a weight of $300-400 \mathrm{~g}$ was placed on the slide to provide pressure from the above and seal the scaffold. Subsequently, the source and sink reservoirs were filled with $250 \mu \mathrm{l}$ of the solution of interest and $250 \mu 1$ of PBS, respectively. The scaffold was then treated for 1, 2 or 4 hours. The solutions in the two reservoirs were then removed using a $200 \mu \mathrm{l}$ pipette. The glass cover slide was carefully and slowly lifted off the scaffold and the scaffold was transferred to $500 \mu$ l of PBS using tweezers. After immersing for $5 \mathrm{~min}$, the scaffold was dabbed on a Kim wipe to remove excess liquid. 

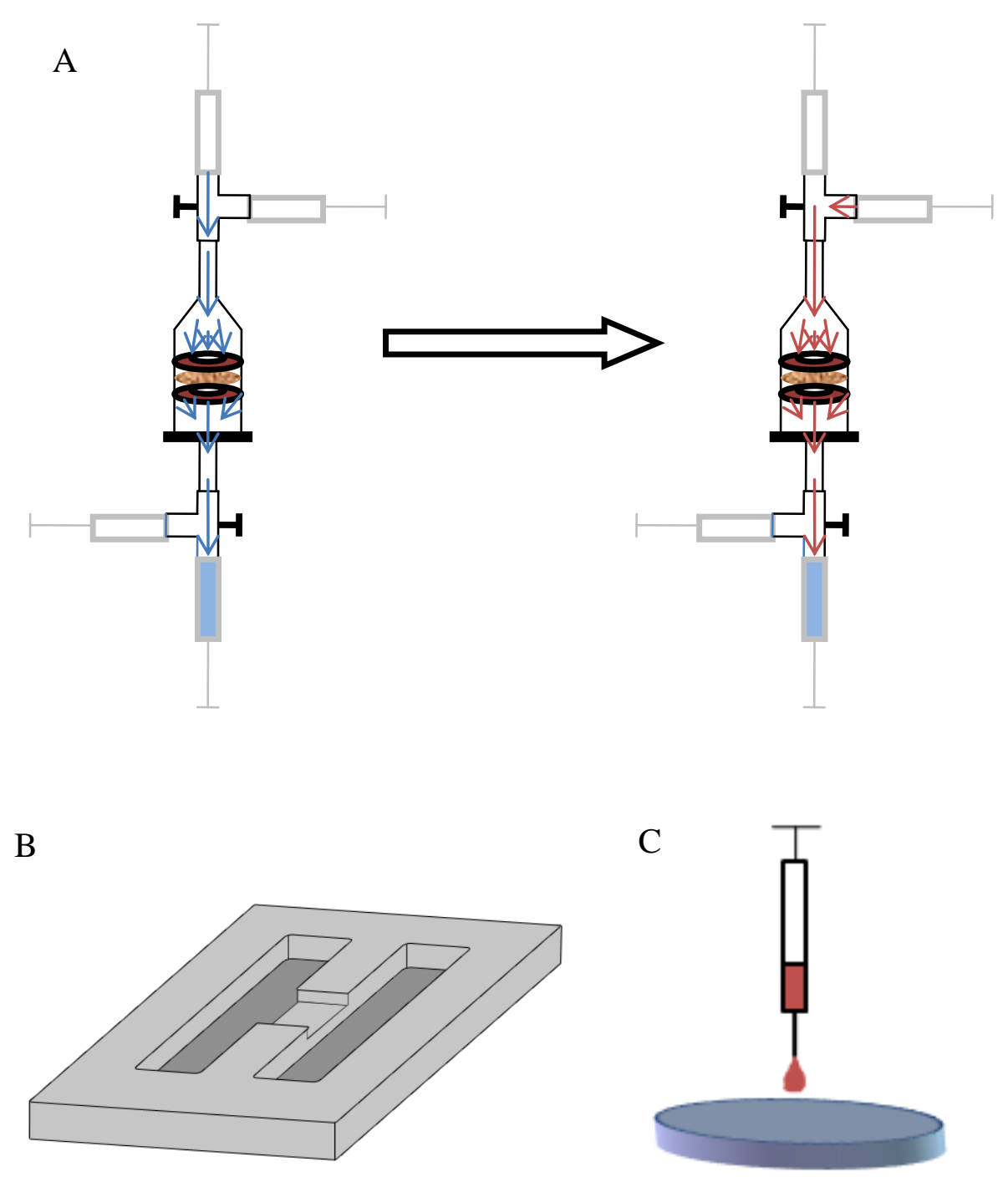

Figure 1. Overview of the gradient generation methods. (A) The Flow Method. The scaffold was placed in a bioreactor connected with two syringes at both ends. The scaffold was first perfused with PBS solution (left, blue arrows). Another syringe with the solution of interest was then used to inject the solution through the center of the scaffold (right, red arrows). The solution passed through the center of the scaffold and diffused towards the periphery. (B) The Sink-source Method. The polycarbonate device was engraved using a counter-top milling machine. The scaffold was mounted on the center platform. The Source compartment contained the solution of interest and the Sink compartment 
contained the blank PBS solution. The solution of interest diffused from the source compartment to the sink through the scaffold. (C) The Point-source Method. The wet scaffold was placed on a flat surface. The solution of interest was then introduced at the center of the scaffold by a mounted syringe and diffused outwards in a radial direction.

\subsubsection{Point-source Method}

The point-source method schematic is shown in Fig. 1c. The 12-mm diameter scaffold discs were placed in $400 \mu \mathrm{l}$ of PBS in a 48-well plate for 20 minutes in order to pre-wet the scaffold. The scaffolds were then placed on autoclaved Kim wipes to remove excess fluid and then transferred to a new 24-well plate. The scaffolds were spread across the plate surface with autoclaved tweezers. Next, a $10 \mu l$ glass syringe (Hamilton, 7653-01), filled with the solution of interest, was mounted on a micromanipulator in an upright position and then positioned about 2 inches above the center of the scaffold. The syringe was equipped with a 22-gauge needle (Hamilton, 7770-02) and was then lowered slowly using the micromanipulator until the needle tip touched the scaffold surface. The solution was then injected into the scaffold. After 1 hour, the process was either repeated for the scaffolds with immobilized growth factor or the scaffolds were washed 8 times in $1 \mathrm{ml}$ PBS for 5 minutes each. 


\subsection{Concentration Profile Characterization}

The concentration gradient profiles formed by the gradient generation methods were visualized using $1 \mathrm{mg} / \mathrm{ml}$ of bovine serum albumin (BSA) conjugated with a fluorescent dye (Alexa-594) (Invitrogen, A13101). After washing the scaffold, it was placed on a microscope glass slide and imaged under a fluorescence microscope at the excitation of $590 \mathrm{~nm}$ and emission of $622 \mathrm{~nm}$. The images were viewed in ImageJ (US National Institutes of Health) and the Plot Profile function was used to quantify the fluorescence intensity as a function of the horizontal position on the scaffold. Insets in Fig. 2 show the position of the boxes drawn for characterizing plot profiles.

\subsection{Method Validation}

Further validation of the Point-source method was carried out by quantifying the fluorescence intensity and immobilizing a model protein, horseradish peroxidase (HRP) on the scaffold. HRP has a similar molar mass as VEGF-165 and was used previously as a model protein for covalent immobilization of linear gradients in $12 \mathrm{~mm}$ thick porous silk scaffolds [64]. In order to quantify the amount of protein in the scaffold, the circular scaffold was sectioned into three rings of increasing diameters $(2,6$ and $8 \mathrm{~mm})$ using two borers of different sizes ( 2 and $6 \mathrm{~mm}$ ). Each of the rings were then immersed in $150 \mu \mathrm{l}$ of $0.276 \mathrm{mg} / \mathrm{ml}$ Collagenase Type IA (Sigma Aldrich, C9891) in a 96-well plate for 1 hour for digestion. Several collagen digestion enzymes were tested for their effect on VEGF and Collagenase Type IA was confirmed to have no effect on the VEGF detection (see Appendix). Following this, the plate was read on a Fluorescence Spectrophotometer (Apollo) at $590 \mathrm{~nm}$ excitation and $622 \mathrm{~nm}$ emission to quantify the amount of Alexa-594 BSA on the scaffold. 
$\mathrm{HRP}$ is a $44 \mathrm{kDa}$ protein that contains free amine groups that can participate in the 1-Ethyl-3-(3-dimethylaminopropyl)carbodiimide/Sulfo N-hydroxysuccinimide (EDC/SNHS) reaction with the carboxyl groups on collagen scaffold. To first confirm the compatibility of HRP with EDC/S-NHS chemistry, it was immobilized uniformly within collagen scaffolds. For this, the scaffolds were activated in $250 \mu \mathrm{l}$ of $(24 \mathrm{mg}$ EDC +60 mg S-NHS) / ml in PBS (Sigma Aldrich, 16142 / Piece, 24510) for 20 minutes and transferred to $250 \mu \mathrm{l}$ of $0.01,0.1$ or $1 \mathrm{mg} / \mathrm{ml} \mathrm{HRP}$ in PBS at room temperature for 1 hour. Following the reaction, the scaffolds were washed 8 times in $1 \mathrm{ml}$ of PBS for 5 minutes per wash.

After the initial screening of the chemistry, HRP was immobilized using the Pointsource Method. The solution of interest was $0.1 \mathrm{mg} / \mathrm{ml} \mathrm{HRP} \mathrm{with}(24 \mathrm{mg}$ EDC $+60 \mathrm{mg}$ S-NHS) / $\mathrm{ml}$ in PBS. The scaffold was sectioned into rings as described above and collagenase digested. To quantify the amount of HRP present in the digested solution, 100 $\mu 1$ of 2,2'-Azino-bis(3-ethylbenzothiazoline-6-sulfonic acid) (ABTS) (Sigma Aldrich, A3219) was added to $100 \mu \mathrm{l}$ of solution. ABTS is a substrate for HRP that undergoes a colorimetric reaction in a time span of $\sim 5$ minutes. The color change was monitored on a plate reader (Apollo LB911) at $405 \mathrm{~nm}$. The amount of HRP was calculated based on standard curve readings of known amounts of HRP. 


\subsection{VEGF Immobilization}

Following the validation of the Point-Source Method, a VEGF gradient was created using this method on a collagen scaffold using the EDC/S-NHS chemistry. After wetting the scaffold in PBS and removing excess fluid, the syringe was filled with $1 \mu \mathrm{g} / \mathrm{ml}$ murine VEGF-165 (Peprotech, 900-K99) and (24 mg EDC + 60 mg S-NHS) / $\mathrm{ml}$ in PBS. The solution was injected into the center of the scaffold in $5 \mu 1$ volumes either once or 3 times, leaving 1 hour for the reaction following each injection. The solution was prepared fresh before each injection. The scaffolds were then washed 8 times in $1 \mathrm{ml}$ of PBS for 5 minutes for each wash. Scaffolds with uniformly immobilized VEGF and no VEGF were used as the controls. Blank scaffolds containing no VEGF were prepared in the same way as the gradient scaffolds described above, with the only change being the absence of VEGF in the solution of interest. For the uniform immobilization, the scaffolds were first activated in $250 \mu \mathrm{l}$ of (12 mg EDC + $30 \mathrm{mg} \mathrm{S-NHS)/} \mathrm{ml}$ in PBS for 20 minutes in a 24well plate. They were then transferred to a fresh well containing $250 \mu \mathrm{l}$ of $100 \mathrm{ng} / \mathrm{ml}$ solution of VEGF for 1 hour. Both the blank and the uniform scaffolds were subjected to 8 washes in $1 \mathrm{~mL}$ of PBS for 5 minutes per wash.

\subsection{VEGF Quantification}

After processing and digesting the cut scaffold sections, the solutions were analyzed using murine VEGF-165 ELISA kit (Peprotech, 900-K99). For this, the manufacturers protocol was followed, the only modification being that instead of the manufacturer-supplied VEGF for the standards, the VEGF that was used for immobilization in the experiments was used. Briefly, the ELISA plates (NUNC Maxisorp, 4420404) were coated with $100 \mu 1$ 
of $100 \mu \mathrm{g} / \mathrm{ml}$ primary antibody overnight at room temperature. After washing the plate 4 times with the wash buffer, the wells were blocked with $300 \mu$ l of blocking buffer for at least 1 hour. The plate was then washed 4 times with wash buffer. Then, $100 \mu 1$ of samples or standards were added in triplicates to the wells. After at least 2 hours of incubation at room temperature, the plate was washed 4 times with wash buffer and 100 $\mu 1$ of detection antibody solution was added. After another 2 hours of incubation, the plate was washed 4 times with wash buffer and $100 \mu$ l of enzyme solution was added to each well. After 30 minutes of incubation, the plate was washed 4 times with wash buffer and $100 \mu 1$ of the ABTS substrate was added to each well. The plate was monitored for up to $35 \mathrm{~min}$ and was read at $405 \mathrm{~nm}$ for absorption every 5 minutes. The time point that provided the best standard curve was used for further analysis.

\subsection{Cell Studies}

\subsubsection{Cell Culture}

The cell type used in this study is D4T endothelial cells (ECs). They are from an embryoid body-derived mouse EC line and are propagated in culture medium (D4T medium) consisting of Iscove's Modified Dulbecco's Media (IMDM, Gibco, 12440-053) with 5\% fetal bovine serum (FBS, Gibco, 16000-044), 100 units/mL penicillin, and 100 $\mu \mathrm{g} / \mathrm{mL}$ streptomycin (Gibco/Invitrogen, 15140122) [65]. This cell line has previously been used by our lab for cardiac tissue engineering studies $[52,66]$. The cells used in this study are between the passages of 10 and 20 . 


\subsubsection{Cell Migration Study}

Following the immobilization of the growth factor on the scaffold, the scaffolds were placed in $500 \mu \mathrm{l}$ of D4T culture medium in the incubator for 30 minutes in order to wet them with culture medium. Several methods of cell seeding on the scaffolds were investigated and the best one was chosen (see Appendix). The scaffolds were placed in the bottom of a 48-well tissue culture plate (BD Scientific, 353230) and the cell suspension (5000 cells / $500 \mu \mathrm{l}$ culture medium) was added on top of the scaffolds. The plate was centrifuged at $1000 \mathrm{rpm}$ for 5 minutes in a plate centrifuge to spin the cells down on the scaffolds. There were three experimental groups: (i) scaffolds with VEGF gradient; (ii) scaffolds with uniformly immobilized VEGF; and (iii) scaffolds with no VEGF. After the centrifugation step, the remaining culture medium was aspirated out and the scaffolds were placed in an incubator at $37{ }^{\circ} \mathrm{C}$ and $5 \% \mathrm{CO}_{2}$ for 40 minutes for the cells to attach to the scaffold. Then, $1 \mathrm{ml}$ of culture medium was added to each well containing the scaffold and the plate was returned to the incubator. After 3 days of culture, the scaffolds were removed from the incubator. The culture medium was aspirated and the scaffolds were stained for Live/Dead markers by incubating the scaffolds in $400 \mu \mathrm{l}$ of the staining solution $(1.5 \mu \mathrm{l}$ carboxyfluorescein diacetate and $75 \mu 1$ propidium iodide in $1 \mathrm{ml}$ PBS) for 40 minutes, as published previously [66]. The scaffolds were then imaged under the fluorescence microscope with the blue filter in order to visualize the live cells.

To study the cell distribution on the scaffold, images were taken at $4 \mathrm{X}$ along the two diameter axis on the scaffold. The surface on which the cells were spun down was imaged for each scaffold. Serial images were taken along the axes and the cell count in 
each image was determined using ImageJ's cell counter function. To maintain consistency, only the cells in the top layer (and not the bleed through) were counted on each image. 


\section{Chapter 3}

Results

\section{Results}

\subsection{Concentration Profiles}

The fluorescence intensity profiles of Alexa-594 BSA for all three methods are given in

Fig. 2. For both the Flow Method and the Point-source Method, the center of the scaffold , showed the highest fluorescent intensity. This was expected since the solution of interest penetrated the scaffold in the center and diffused towards the periphery. Consequently, the intensity dropped from the center towards the periphery. Although not shown, the profile was identical in other directions as well. The concentration profile of the Source/Sink method was different from the other two methods since the solution of interest penetrated the scaffold on one side and diffused towards the other. Hence, the intensity profile was highest on the side closest to the reservoir containing the solution of interest and lowest on the blank reservoir side. The resulting profile was dependent on the time period allowed for diffusion.

The Sink-source method suffered from lack of reproducibility and uneven VEGF distribution (Fig. 3). In comparison, the Point-source method and the Flow method offered superior reproducibility. In addition, these two methods generated a radial gradient starting in the center, in contrast to the linear gradient generated by the Sinksource method. The radial gradient meets our design criteria of promoting cell migration towards the scaffold center. Of these two methods, the Point-source method provided a 
smoother profile and was technically simpler than the Flow-method. Importantly, the Point-source method uses significantly smaller amounts of reagents because all of the starting solution of interest is injected into the scaffold. Hence, only the Point-source Method was used for further experimentation.

A

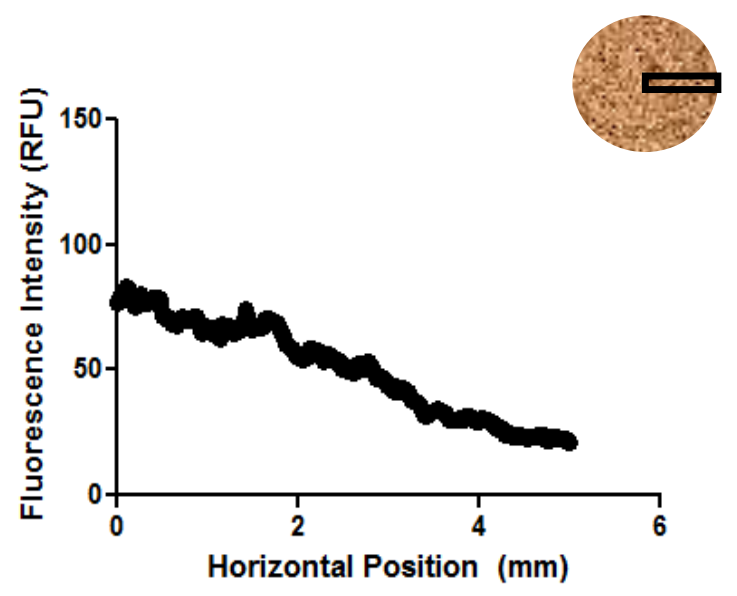

C

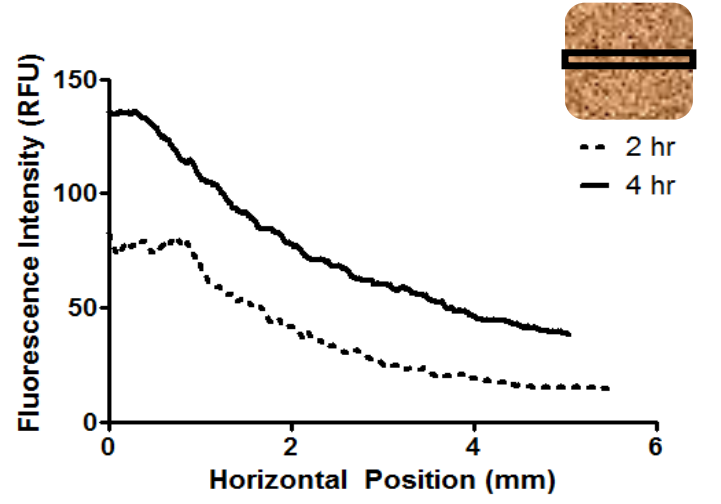

B

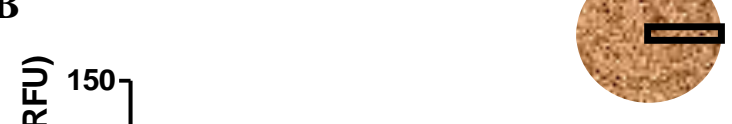

Figure 2. Fluorescence Intensity profiles of Alexa-594 BSA for the three gradient

generation methods. (A) The Flow method. (B) The Point-source method. (C) The Sinksource method. The profiles are as they appear looking from the top of the scaffold, as shown in the insets. The zero point on the x-axis corresponds to the center of the scaffold in (A) and (B) and the Source edge of the scaffold in (C). As expected both (A) and (B) show the highest concentration at the center of the scaffold, the point of injection of the dye, which then drops off moving towards the periphery. Similarly, (C) shows the highest 
concentration at the Source edge of the scaffold which drops off moving towards the Sink side. (one representative curve shown, $n=3$ )
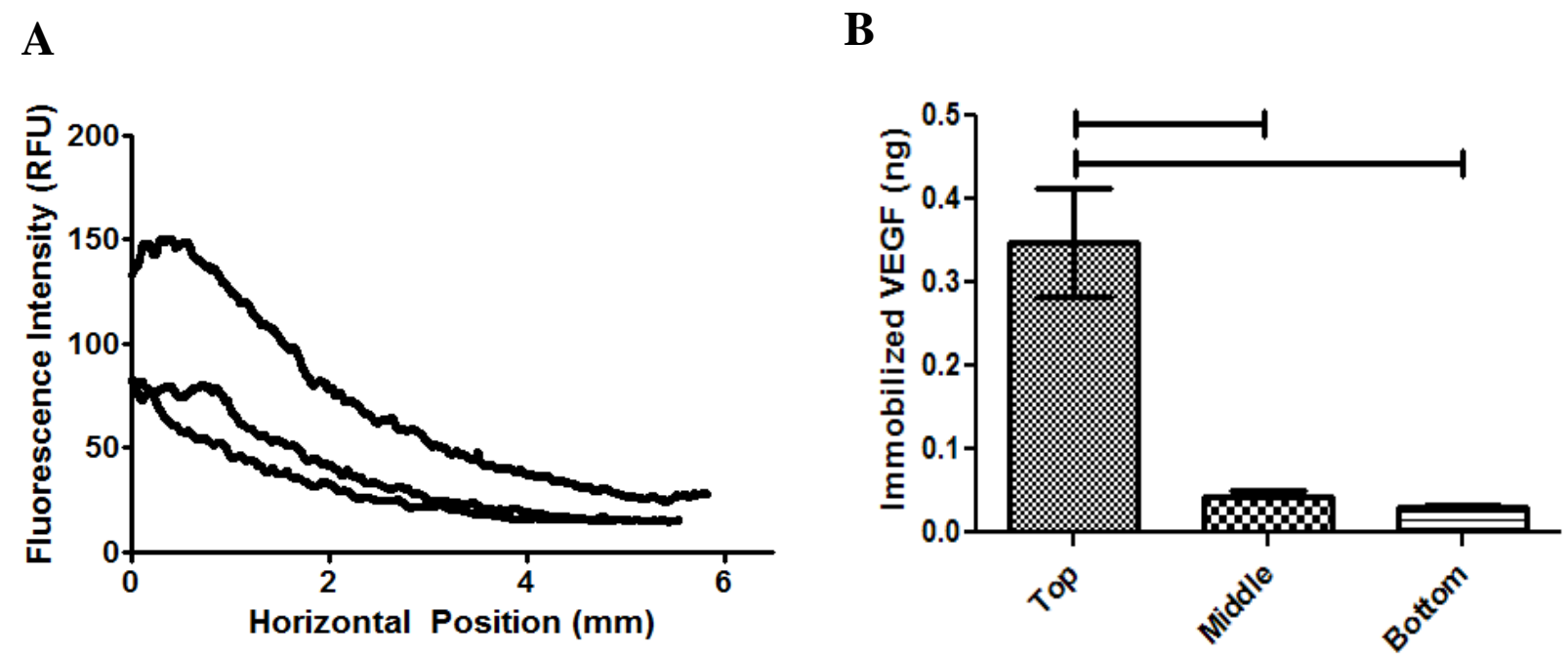

Figure. 3. The Sink-source method suffers from lack of reproducibility and uneven VEGF distribution. (A) The intensity profile was measured for three different trials for the same time period ( $2 \mathrm{~h}$ ) of diffusion of BSA-Alexa-594. The curves show large variance between trials and hence, the reproducibility of this method is low. (B) The amount of VEGF in each of the three sections of the scaffold was quantified using VEGF ELISA. Most of the VEGF was found in the section closest to the Source compartment (Top). This suggests that the VEGF accumulated at one end of the scaffold and did not diffuse towards the other end. Lines above the bars indicate statistical difference. $(n=3)$ 


\subsection{Point-source Method}

The gradients of three different proteins processed by the Point source method were compared by quantifying the concentration in three concentric circular rings of the collagen scaffold after digestion in collagenase: BSA-Alexa-594, HRP and VEGF (Fig.

4). The intensity profile was normalized to the surface area of each of the collagen scaffold rings. HRP has a similar molar mass as VEGF and was used previously as a model protein for covalent immobilization of linear gradients in $12 \mathrm{~mm}$ thick porous silk scaffolds [64]. As expected, the center regions of the scaffold contained the maximum amount of protein since the protein solution was introduced there. The amount of protein decreased from the center towards the periphery. Interestingly, three serial injections of VEGF solutions led to $3.8 \pm 0.4$ times higher amount of VEGF-165 immobilized $(0.27 \pm$ $0.03 \mathrm{ng})$ compared to one injection $(0.07 \pm 0.01 \mathrm{ng})$. In addition, the gradient was steeper with three serial injections $(2.35 \mathrm{ng} / \mathrm{ml} / \mathrm{mm})$ compared to a single injection $(0.64$ ng/ml/mm) (Fig. 4c). 
A

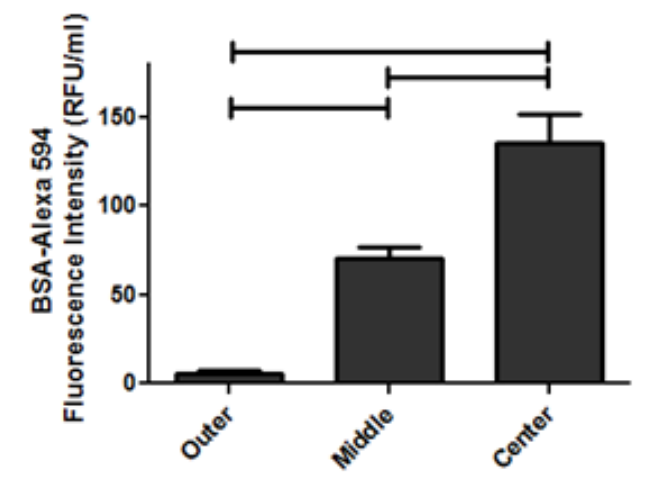

C

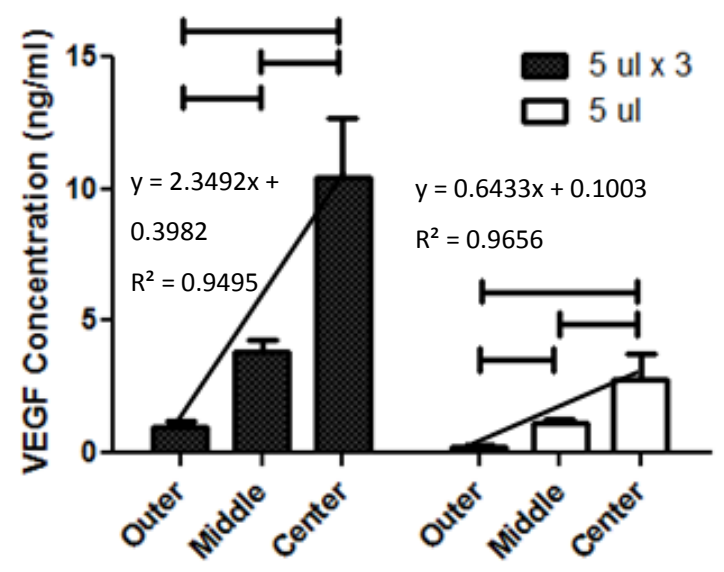

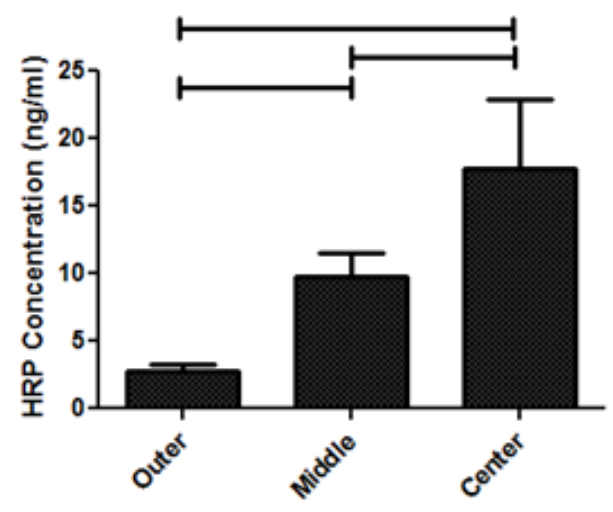

Figure 4. Protein quantification for the Point-source method. Scaffolds were either injected with Alexa-594 labeled BSA or covalently immobilized with either HRP or VEGF using the Point-source method. The scaffolds were then sectioned into three concentric rings and digested in collagenase. The protein content in each ring was measured and normalized to the calculated volume. (A) Alexa 594-BSA (B) HRP (C) VEGF. Error bars indicate standard deviation. Lines above the bars indicate statistical difference. $(n=4-6)$ 


\subsection{Cell Studies}

Having created a well-defined concentration gradient in scaffolds, we next examined cell distribution on the scaffolds with a VEGF gradient vs. a homogenous concentration of VEGF vs. no VEGF (controls). As shown in Fig. 5, the scaffolds with the gradient of VEGF resulted in a distribution of cells that mirrored the VEGF gradient, with a higher cell concentration in the center and a lower one at the periphery. The scaffolds with uniform VEGF had a distribution that also mirrored the concentration of VEGF - that is a relatively uniform cell distribution along the radius. Similarly, the scaffolds without immobilized VEGF had a more uniform distribution of VEGF, but a trend towards a lower total cell number compared to the scaffolds with uniformly immobilized VEGF. Importantly, the total amount of immobilized VEGF was comparable (and not significantly different) in the gradient scaffold $(0.27 \pm 0.03 \mathrm{ng})$ and uniformly immobilized scaffold $(0.38 \pm 0.09 \mathrm{ng})$. 


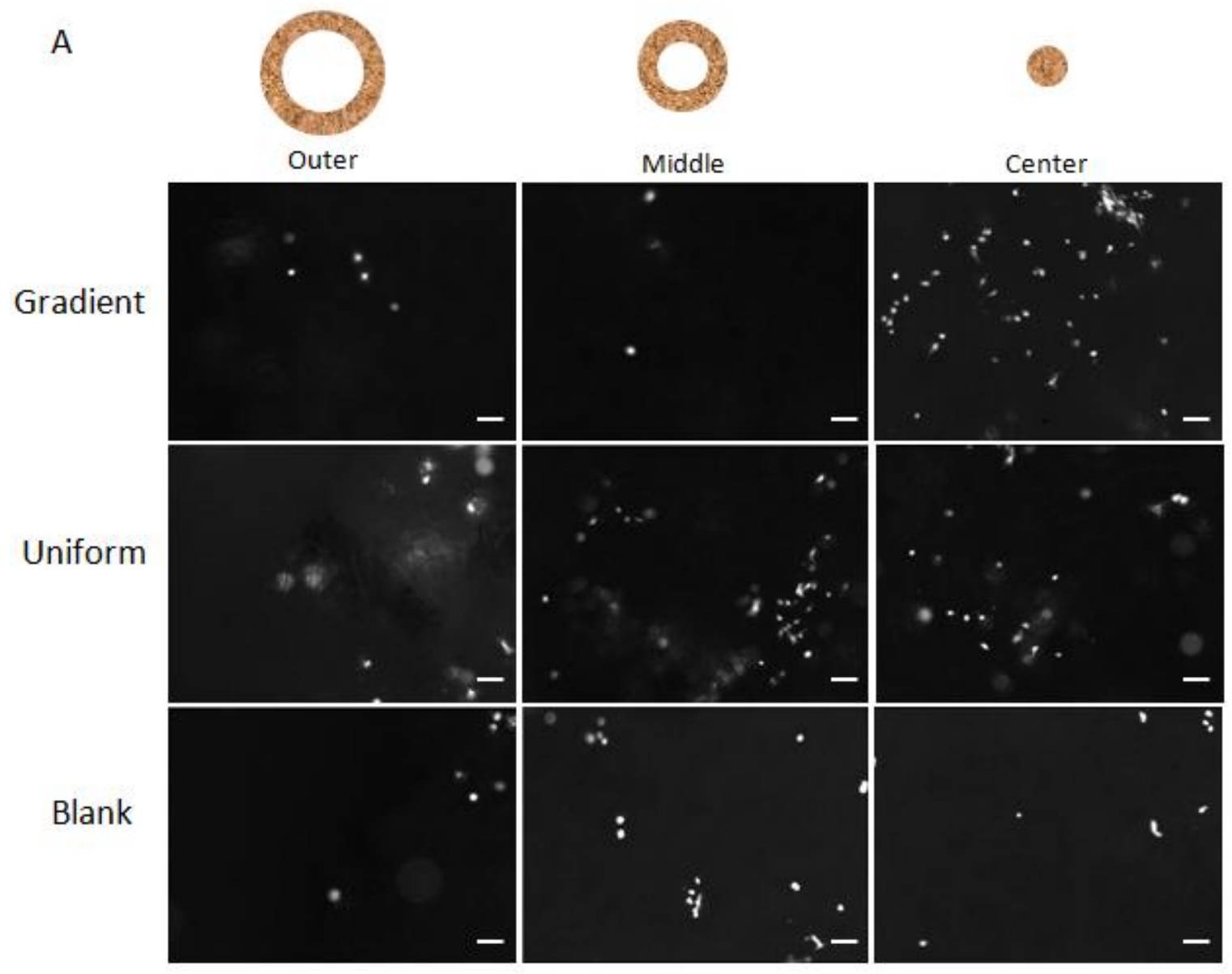

B

C
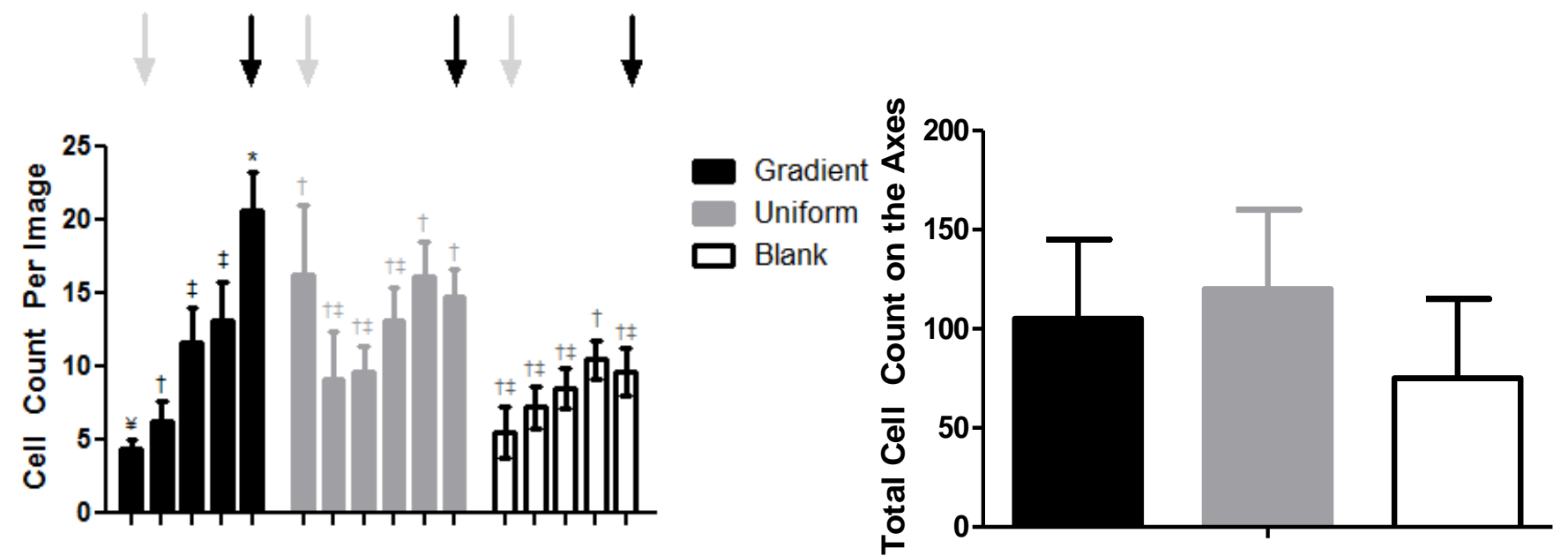

Gradient

Uniform

$\square$ Blank 
Figure 5. Scaffolds with gradients lead to a more centralized cell distribution. (A) The scaffolds prepared with the point-source method were seeded with 5000 cells and cultured for 3 days. At the end of the culture period, the scaffolds were stained for the live cell marker, CFDA. Serial images were acquired on the two axes on the circular scaffold. (B) The cell density of each image was counted using ImageJ. The plot shows the cell distribution on the scaffolds. The X-axis spans the radius of the scaffold for each group. Black and white arrows indicate the scaffold center and periphery of the scaffold, respectively. (C) The number of cells along the diameter of the scaffold was calculated by adding the number of cells in each image along the two axes of the scaffold. Error bars indicate standard error. Data points with the same symbol indicate groups without statistically significant difference $(p<0.05) .(n=4-6)$. Scale bar, $500 \mu \mathrm{m}$. 


\section{Chapter 4 \\ Discussion}

\section{Discussion}

Engineered Heart Tissues (EHTs) suffer from poor cell survival in the center regions of the constructs due to poor oxygen and nutrient supply [67]. Although strategies such as growth factor immobilization have partially succeeded in enhancing cell survival and proliferation, there still remains the need for a more long-term and natural process of enhancing the cell survival in the center of the scaffolds.

Soluble and immobilized gradients of growth factors have been shown to direct cell migration mainly on 2D surfaces or microfluidic channels. Tissue engineering scaffolds with incorporated immobilized gradients of growth factors would promote and direct the growth of new blood vessels and consequently, support the survival of the cells in the depths of the scaffold. However, the first step to achieving this goal is to promote endothelial cell migration on the scaffolds. In this study, we aimed to investigate the effect of an immobilized gradient of VEGF, an essential growth factor in the process of angiogenesis, on porous collagen scaffolds.

The creation of gradients on collagen scaffolds represents an important advance because collagen scaffolds alone have already been shown to be cytocompatible in vitro and biocompatible in vivo [54]. Since photochemical and lithographic techniques would not work in the opaque collagen scaffold, the point source method, albeit simple, was effective in creating a gradient scaffold within which we could guide cell growth. 
Importantly, this was achieved on a mm scale, which is larger than most microscale systems and thus a step closer to clinical requirements $[58,59]$.

A number of factors are known to promote angiogenesis: VEGF, acidic fibroblast growth factor (aFGF), basic fibrobalast growth factor (bFGF), angiogenin, placenta growth factor, epidermal growth factor (EGF)/transforming growth factor $\alpha$ (TGF- $\alpha$ ) and hepatocyte growth factor [68]. Although many of these may act on endothelial cells, VEGF and FGF are the two major ones. Others either exert their effects by increasing the levels of these two factors, for example how TGF- $\alpha$ stimulates expression of VEGF, or by working synergistically to augment the actions of these factors [69]. The FGF family of proteins have been shown to promote endothelial cell migration and proliferation in some studies [70-72]. However FGF binds to receptors on multiple cell types including smooth muscle cells and fibroblasts. VEGF, on the other hand, receptors are predominantly found on endothelial cells only. In addition, it is the single most important and most studied growth factor in the literature [73]. Hence, while not overlooking the importance of other growth factors, the investigation of only VEGF in this study provides an important step forward in the field of regenerative angiogenesis.

The bioactivity of VEGF-165 has been previously reported to be either unaffected or enhanced due to covalent immobilization. Aizawa et. al. measured the proliferation of endothelial cells in the presence of either immobilized or soluble forms of VEGF-165. It was found that, for approximately the same amounts of VEGF-165, the cells showed no difference in their proliferation between the immobilized and soluble groups [60]. Chiu and Radisic found that endothelial cells proliferated significantly more on collagen 
scaffolds immobilized with VEGF-165 and Angiopoietin-1 than on scaffolds supplemented with the soluble forms of the same growth factors [74] We took advantage of the extensive studies done to differentiate between physical adsorption and covalent modification using identical synthetic techniques [54] and focused simply on the VEGF165 immobilized scaffolds and the resulting cell guidance.

The concentration of the immobilized VEGF used in this study was between 3-10 $\mathrm{ng} / \mathrm{ml}$. Previous reports of immobilized VEGF have observed cell response to a broad range of concentrations. There are reports of high concentrations of VEGF: Aizawa et. al. examined concentrations on the order of 400-2000 ng/ml [60]; Chiu and Radisic used concentrations of approximately $750 \mathrm{ng} / \mathrm{ml}$ [54]; and Shen. et. al. reported concentrations of 40 and $110 \mathrm{ng} / \mathrm{ml}$ on collagen scaffolds [52]. There are also reports of lower concentrations of VEGF:. Chung et. al. used concentration gradients ranging between 0 and $20 \mathrm{ng} / \mathrm{ml}$ in a microfluidic channel [59]; Shamloo et. al. used concentrations ranging between 18 and $32 \mathrm{ng} / \mathrm{ml}$, with the average concentration being $25 \mathrm{ng} / \mathrm{ml}$ in soluble forms [58]. Hence, there is a wide concentration range over which endothelial cells in general, and D4T endothelial cells in particular, respond to VEGF concentrations. Interestingly, the results of the current study confirm that D4T endothelial cells are able to respond to VEGF cues in the range of 3-10 ng/ml.

The cell distribution profile for the gradient scaffolds shows a Gaussian-like profile where more cells are present at the center region of the scaffold, thereby mimicking the VEGF gradient which is also highest in the center. The correlation in VEGF gradient with cell distribution suggests that the D4T cells are guided up the VEGF 
concentration gradient on the collagen scaffolds. The scaffolds with uniformly immobilized VEGF did not exhibit any particular spatial preference for the cells. This is expected since cells see similar amounts of VEGF at all points on the scaffold. A rather surprising result, however, is that the cell distribution on the blank scaffolds exhibits a slight peak. . One particular explanation for this observation is as follows: the peripheries of the scaffolds containing the VEGF gradient may have little or no VEGF present since the VEGF solution starts diffusing from the center of the scaffold. Hence, in these regions, the scaffolds with the gradient may behave similar to the blank scaffolds without VEGF. At these locations, the two groups are expected to show similar cell response. However, the scaffolds containing the gradient show a much more prominent peak in the center, which suggests that VEGF gradient enhances the migration of the cells towards the center.

The distribution of the cells after 3 days on the scaffolds raises an important question: are the cells proliferating/surviving selectively or migrating in response to VEGF gradient on the scaffold? Chiu and Radisic reported that the collagen scaffolds uniformly immobilized with VEGF-165 showed significantly higher number of cells, suggesting a higher proliferation and survival rate on these scaffolds. In order to determine the exact mechanism of cell behavior, the total number of cells/scaffold was counted and found not to be significantly different as shown in Fig. 5c. This indicates that the cells did not proliferate in response to the immobilized VEGF-165 but instead migrated, on immobilized VEGF-165 gradients of $\sim 2 \mathrm{ng} / \mathrm{ml} / \mathrm{mm}$. This suggests that the immobilization of VEGF-165, either in a uniform or gradient pattern, does not lead to a higher survival or proliferation of endothelial cells in this 3 day time period. This is 
contrary to the results reported by Chiu and Radisic [74]. This discrepancy can be explained by two major factors. First, the immobilized concentration in the current system is about two orders of magnitude lower than that in the Chiu study (3-10 ng/ml vs. 750 $\mathrm{ng} / \mathrm{ml})$. It is possible that higher VEGF-165 levels are able to promote cell migration but not proliferation. Second, the cell density used in this study is lower than that used by Chiu (5000 vs 50,000 cells per scaffold). Since one of the factors that govern the cell-cell interactions is cell density, this reduction in cell number is expected to affect the cell response.

The creation of growth factor gradients on collagen scaffolds as described here represents an important advance since photochemical and lithographic techniques would not work in the opaque porous scaffolds. The point source method, albeit simple, was effective in creating a gradient of immobilized VEGF-165 in the scaffold and could be extended to many other porous scaffold types since it utilizes water soluble EDC chemistry at physiological $\mathrm{pH}$. The method enables gradient generation in pre-formed scaffolds without the need to polymerize/fabricate the scaffold concurrently with the gradient generation. The collagen scaffolds used here have already been demonstrated to be cytocompatible in vitro and biocompatible in vivo, thus the ability to guide cells deeper into the scaffold interior may overcome the formation of necrotic cores normally observed during a tissue engineering process and upon implantation. Importantly, gradient creation was achieved on millimetre-scale scaffolds, which is larger than most microscale systems and thus closer to clinical requirements $[58,59]$. 


\section{Chapter 5 \\ Conclusion}

\section{Conclusion}

We reported three methods of generating protein gradients on collagen scaffolds, with the Point source method being the most facile and reproducible of the three tested. The VEGF-165 gradient $(\sim 2 \mathrm{~nm} / \mathrm{ml} / \mathrm{mg})$ immobilized in a radial direction in a $12 \mathrm{~mm}$ diameter collagen scaffold guided endothelial cells deep into the center of the scaffold compared to the uniformly immobilized VEGF-165 and the VEGF-free controls. The migration of cells deep into the scaffold rather than proliferation in the scaffold interior was substantiated by the similar numbers of cells on the different scaffolds.

Interestingly, these effects were observed even with very low concentrations of immobilized VEGF-165, indicating that high concentrations are not necessarily required to observe cell guidance. The developed gradient-scaffolds may be used to guide cells into the scaffold interior during a tissue engineering process and upon implantation. 


\section{Chapter 6 \\ Future Directions}

\section{Future Directions}

The most important product of this project was the development of the gradient generation methods. The simplicity and universality of the methods enable them to be applicable in a wide range of applications in tissue engineering. Any factor can be substituted for the VEGF; for example a gradient of nerve growth factor can be established in a gel for guided neurite growth [75] or a gradient of RGDS peptide can be used to study the migration of fibroblasts [76]. The immobilization chemistry can be readily changed to any other water-based systems than EDC/S-NHS by simply switching the cross-linker in the reaction solution.

The biological effect of the VEGF gradient on endothelial cells, as demonstrated in this project, complements the previous literature and opens the door to a variety of applications in tissue engineering [59, 60]. Pre-vascularization of constructs is a major challenge in cardiovascular tissue engineering. This project advances the current progress in vascular tissue engineering by demonstrating the potential of gradients of biological growth/survival factors such as VEGF to exhibit their effects in 3D, pre-formed, porous and opaque scaffolds such as collagen. The Radisic lab is currently working on many projects for cardiovascular tissue engineering: implantable pre-seeded collagen scaffolds and hydrogels with immobilized growth factors for stem cell differentiation to name a few. Regardless of their design, all projects require a vascular system within the construct to support cell survival and integration in the host tissue. Similarly, the Shoichet lab works on several projects focusing on implantable tubes and hydrogels for spinal cord 
regeneration. Some of the projects require spatial and temporal control over the growth of axons and hence, gradients prove useful in these applications.

The primary focus of this project was on endothelial cell migration in response to VEGF gradient. For a successful vascular development, the cells need to migrate as well as proliferate. In addition, other cell types such as fibroblasts and smooth muscle cells play a vital role in the process as well [73]. It would be useful to optimize the immobilized VEGF concentration to induce both migration as well as proliferation of the cells. This may require changing the immobilization chemistry to something that offers higher immobilization efficiency. Once endothelial cells demonstrate the synergistic effects of migration and proliferation, their assembly into tube-like structures can be investigated, similar to the method reported by Chiu et. al. [54]. Next, fibroblast and smooth muscle cells can be added along with additional growth factors, such as angiopoietin I or fibroblast growth factor, to study the process of vessel formation within the scaffold.

It would also be interesting to see the effect of changing the cell density as well as the cell type on the gradient response. The steepness of the gradient, as well as the boundary concentrations, are some of the other factors that are expected to have an effect on the cell response. The cell response was primarily analyzed in the xy plane of the scaffold; analysis in the z-axis could be useful since when implanted, the host cells surround the scaffold from all directions. Although the analysis of the cell migration as a whole presents a useful finding, further analysis at a micro-scopic level would enhance our understanding of the exact nature and amount of cell migration. For this purpose, the cells can be tagged with a fluorescent dye, such as the Cell Tracker dye used previously 
[66], and tracked. The paths of their migration can be traced and analyzed to calculate the direction and magnitude of the migration. Immobilization of growth factors to the scaffold can lead to interference with their normal biological activity if the covalent bonds formed in the immobilization process utilize functional groups located in the receptor-binding domain of the growth factor. In the case of EDC chemistry, carboxyl groups on one molecule react with amine groups on the other molecule. Hence, the probability of the interference due to immobilization depends on the number of carboxyl and amine groups that are located in the receptor-binding site of the growth factor. Chiu et. al. has performed statistical analysis for the probability of EDC chemistry affecting the receptorbinding regions of VEGF for both step and bulk immobilization. The probability of interference was calculated to be $23 \%$ for step immobilization and $32-38 \%$ for bulk immobilization [77]. Despite the fact that biological response of the cells was observed in this study towards the VEGF immobilization, this interference should be considered in future for the purposes of enhancing endothelial response to the immobilized VEGF, as well as, choosing an alternative immobilization method. 


\section{Chapter 7 \\ References}

\section{$7 \quad$ References}

[1] American Heart Association Cardiovascular Disease Data.

[2] Jawad H, Lyon AR, Harding SE, Ali NN, Boccaccini AR. Myocardial tissue engineering. Br Med Bull. 2008;87:31-47.

[3] Rakusan K, Flanagan MF, Geva T, Southern J, Van Praagh R. Morphometry of human coronary capillaries during normal growth and the effect of age in left ventricular pressure-overload hypertrophy. Circulation. 1992;86:38-46.

[4] Vunjak-Novakovic G, Tandon N, Godier A, Maidhof R, Marsano A, Martens TP, et al. Challenges in cardiac tissue engineering. Tissue Eng Part B Rev.16:169-87.

[5] Christman KL, Lee RJ. Biomaterials for the treatment of myocardial infarction. J Am Coll Cardiol. 2006;48:907-13.

[6] Langer R, Vacanti JP. Tissue engineering. Science. 1993;260:920-6.

[7] Amado LC, Saliaris AP, Schuleri KH, St John M, Xie JS, Cattaneo S, et al. Cardiac repair with intramyocardial injection of allogeneic mesenchymal stem cells after myocardial infarction. Proc Natl Acad Sci U S A. 2005;102:11474-9.

[8] Silva GV, Litovsky S, Assad JA, Sousa AL, Martin BJ, Vela D, et al. Mesenchymal stem cells differentiate into an endothelial phenotype, enhance vascular density, and improve heart function in a canine chronic ischemia model. Circulation. 2005;111:150-6.

[9] Klug MG, Soonpaa MH, Koh GY, Field LJ. Genetically selected cardiomyocytes from differentiating embronic stem cells form stable intracardiac grafts. J Clin Invest. 1996;98:216-24.

[10] Caspi O, Lesman A, Basevitch Y, Gepstein A, Arbel G, Habib IH, et al. Tissue engineering of vascularized cardiac muscle from human embryonic stem cells. Circ Res. 2007;100:263-72.

[11] van Laake LW, Passier R, Doevendans PA, Mummery CL. Human embryonic stem cell-derived cardiomyocytes and cardiac repair in rodents. Circ Res. 2008;102:1008-10.

[12] Gimble JM, Katz AJ, Bunnell BA. Adipose-derived stem cells for regenerative medicine. Circ Res. 2007;100:1249-60.

[13] Planat-Benard V, Menard C, Andre M, Puceat M, Perez A, Garcia-Verdugo JM, et al. Spontaneous cardiomyocyte differentiation from adipose tissue stroma cells. Circ Res. 2004;94:223-9. 
[14] Menasche P. Skeletal myoblast for cell therapy. Coron Artery Dis. 2005;16:105-10.

[15] Laugwitz KL, Moretti A, Lam J, Gruber P, Chen Y, Woodard S, et al. Postnatal isl1+ cardioblasts enter fully differentiated cardiomyocyte lineages. Nature. 2005;433:647-53.

[16] Smith RR, Barile L, Cho HC, Leppo MK, Hare JM, Messina E, et al. Regenerative potential of cardiosphere-derived cells expanded from percutaneous endomyocardial biopsy specimens. Circulation. 2007;115:896-908.

[17] Narazaki G, Uosaki H, Teranishi M, Okita K, Kim B, Matsuoka S, et al. Directed and systematic differentiation of cardiovascular cells from mouse induced pluripotent stem cells. Circulation. 2008;118:498-506.

[18] Park IH, Arora N, Huo H, Maherali N, Ahfeldt T, Shimamura A, et al. Diseasespecific induced pluripotent stem cells. Cell. 2008;134:877-86.

[19] Ferreira LS, Gerecht S, Fuller J, Shieh HF, Vunjak-Novakovic G, Langer R. Bioactive hydrogel scaffolds for controllable vascular differentiation of human embryonic stem cells. Biomaterials. 2007;28:2706-17.

[20] Vunjak-Novakovic G, Tandon N, Godier A, Maidhof R, Marsano A, Martens TP, et al. Challenges in cardiac tissue engineering. Tissue Eng Part B Rev. 2010;16:169-87.

[21] Siminiak T, Burchardt P, Kurpisz M. Postinfarction heart failure: surgical and transcoronary-venous transplantation of autologous myoblasts. Nat Clin Pract Cardiovasc Med. 2006;3 Suppl 1:S46-51.

[22] Shimizu T, Yamato M, Isoi Y, Akutsu T, Setomaru T, Abe K, et al. Fabrication of pulsatile cardiac tissue grafts using a novel 3-dimensional cell sheet manipulation technique and temperature-responsive cell culture surfaces. Circ Res. 2002;90:e40.

[23] Veenstra RD, DeHaan RL. Electrotonic interactions between aggregates of chick embryo cardiac pacemaker cells. Am J Physiol. 1986;250:H453-63.

[24] Fink C, Ergun S, Kralisch D, Remmers U, Weil J, Eschenhagen T. Chronic stretch of engineered heart tissue induces hypertrophy and functional improvement. FASEB J. 2000;14:669-79.

[25] Zimmermann WH, Melnychenko I, Wasmeier G, Didie M, Naito H, Nixdorff U, et al. Engineered heart tissue grafts improve systolic and diastolic function in infarcted rat hearts. Nat Med. 2006;12:452-8.

[26] Zimmermann WH, Schneiderbanger K, Schubert P, Didie M, Munzel F, Heubach JF, et al. Tissue engineering of a differentiated cardiac muscle construct. Circ Res. 2002;90:223-30.

[27] Radisic M, Park H, Shing H, Consi T, Schoen FJ, Langer R, et al. Functional assembly of engineered myocardium by electrical stimulation of cardiac myocytes cultured on scaffolds. Proc Natl Acad Sci U S A. 2004;101:18129-34. 
[28] Radisic M, Yang L, Boublik J, Cohen RJ, Langer R, Freed LE, et al. Medium perfusion enables engineering of compact and contractile cardiac tissue. Am J Physiol Heart Circ Physiol. 2004;286:H507-16.

[29] Kofidis T, Lenz A, Boublik J, Akhyari P, Wachsmann B, Mueller-Stahl K, et al. Pulsatile perfusion and cardiomyocyte viability in a solid three-dimensional matrix. Biomaterials. 2003;24:5009-14.

[30] Dvir T, Benishti N, Shachar M, Cohen S. A novel perfusion bioreactor providing a homogenous milieu for tissue regeneration. Tissue Eng. 2006;12:2843-52.

[31] Dvir T, Levy O, Shachar M, Granot Y, Cohen S. Activation of the ERK1/2 cascade via pulsatile interstitial fluid flow promotes cardiac tissue assembly. Tissue Eng. 2007;13:2185-93.

[32] Brown MA, Iyer RK, Radisic M. Pulsatile perfusion bioreactor for cardiac tissue engineering. Biotechnol Prog. 2008;24:907-20.

[33] Radisic M, Euloth M, Yang L, Langer R, Freed LE, Vunjak-Novakovic G. Highdensity seeding of myocyte cells for cardiac tissue engineering. Biotechnol Bioeng. 2003;82:403-14.

[34] Radisic M, Marsano A, Maidhof R, Wang Y, Vunjak-Novakovic G. Cardiac tissue engineering using perfusion bioreactor systems. Nat Protoc. 2008;3:719-38.

[35] Radisic M, Park H, Chen F, Salazar-Lazzaro JE, Wang Y, Dennis R, et al. Biomimetic approach to cardiac tissue engineering: oxygen carriers and channeled scaffolds. Tissue Eng. 2006;12:2077-91.

[36] Jiang F, Zhang G, Hashimoto I, Kumar BS, Bortolotto S, Morrison WA, et al. Neovascularization in an arterio-venous loop-containing tissue engineering chamber: role of NADPH oxidase. J Cell Mol Med. 2008;12:2062-72.

[37] Dvir T, Kedem A, Ruvinov E, Levy O, Freeman I, Landa N, et al. Prevascularization of cardiac patch on the omentum improves its therapeutic outcome. Proc Natl Acad Sci U S A. 2009;106:14990-5.

[38] Stevens KR, Kreutziger KL, Dupras SK, Korte FS, Regnier M, Muskheli V, et al. Physiological function and transplantation of scaffold-free and vascularized human cardiac muscle tissue. Proc Natl Acad Sci U S A. 2009;106:16568-73.

[39] Levenberg S, Rouwkema J, Macdonald M, Garfein ES, Kohane DS, Darland DC, et al. Engineering vascularized skeletal muscle tissue. Nat Biotechnol. 2005;23:879-84.

[40] Asakawa N, Shimizu T, Tsuda Y, Sekiya S, Sasagawa T, Yamato M, et al. Prevascularization of in vitro three-dimensional tissues created by cell sheet engineering. Biomaterials.31:3903-9. 
[41] Benest AV, Salmon AH, Wang W, Glover CP, Uney J, Harper SJ, et al. VEGF and angiopoietin-1 stimulate different angiogenic phenotypes that combine to enhance functional neovascularization in adult tissue. Microcirculation. 2006;13:423-37.

[42] Zhu WH, MacIntyre A, Nicosia RF. Regulation of angiogenesis by vascular endothelial growth factor and angiopoietin-1 in the rat aorta model: distinct temporal patterns of intracellular signaling correlate with induction of angiogenic sprouting. Am J Pathol. 2002;161:823-30.

[43] Hosack LW, Firpo MA, Scott JA, Prestwich GD, Peattie RA. Microvascular maturity elicited in tissue treated with cytokine-loaded hyaluronan-based hydrogels. Biomaterials. 2008;29:2336-47.

[44] Yu LM, Miller FD, Shoichet MS. The use of immobilized neurotrophins to support neuron survival and guide nerve fiber growth in compartmentalized chambers.

Biomaterials. 2010;31:6987-99.

[45] Rahman N, Purpura KA, Wylie RG, Zandstra PW, Shoichet MS. The use of vascular endothelial growth factor functionalized agarose to guide pluripotent stem cell aggregates toward blood progenitor cells. Biomaterials. 2010;31:8262-70.

[46] Kuhl PR, Griffith-Cima LG. Tethered epidermal growth factor as a paradigm for growth factor-induced stimulation from the solid phase. Nature Medicine. 1996;2:1022-7.

[47] Fan VH, Tamama K, Au A, Littrell R, Richardson LB, Wright JW, et al. Tethered epidermal growth factor provides a survival advantage to mesenchymal stem cells. Stem Cells. 2007;25:1241-51.

[48] Sahni A, Sporn LA, Francis CW. Potentiation of endothelial cell proliferation by fibrin(ogen)-bound fibroblast growth factor-2. J Biol Chem. 1999;274:14936-41.

[49] Chiang CK, Chowdhury MF, Iyer RK, Stanford WL, Radisic M. Engineering surfaces for site-specific vascular differentiation of mouse embryonic stem cells. Acta Biomater. 2010;6:1904-16.

[50] Neufeld G, Cohen T, Gengrinovitch S, Poltorak Z. Vascular endothelial growth factor (VEGF) and its receptors. FASEB J. 1999;13:9-22.

[51] Olsson AK, Dimberg A, Kreuger J, Claesson-Welsh L. VEGF receptor signalling - in control of vascular function. Nat Rev Mol Cell Biol. 2006;7:359-71.

[52] Shen YH, Shoichet MS, Radisic M. Vascular endothelial growth factor immobilized in collagen scaffold promotes penetration and proliferation of endothelial cells. Acta Biomater. 2008;4:477-89.

[53] Miyagi Y, Chiu LL, Cimini M, Weisel RD, Radisic M, Li RK. Biodegradable collagen patch with covalently immobilized VEGF for myocardial repair. Biomaterials. 2010. 
[54] Chiu LL, Radisic M. Scaffolds with covalently immobilized VEGF and Angiopoietin-1 for vascularization of engineered tissues. Biomaterials.31:226-41.

[55] Koch S, Yao C, Grieb G, Prevel P, Noah EM, Steffens GC. Enhancing angiogenesis in collagen matrices by covalent incorporation of VEGF. J Mater Sci Mater Med. 2006; 17:735-41.

[56] Taguchi T, Kishida A, Akashi M, Maruyama I. Immobilization of Human Vascular Endothelial Growth Factor (VEGF165) onto Biomaterials: An Evaluation of the Biological Activity of Immobilized VEGF165 Journal of Bioactive and Compatible Polymers 2000;15:309-20.

[57] Helm CL, Fleury ME, Zisch AH, Boschetti F, Swartz MA. Synergy between interstitial flow and VEGF directs capillary morphogenesis in vitro through a gradient amplification mechanism. Proc Natl Acad Sci U S A. 2005;102:15779-84.

[58] Shamloo A, Ma N, Poo MM, Sohn LL, Heilshorn SC. Endothelial cell polarization and chemotaxis in a microfluidic device. Lab Chip. 2008;8:1292-9.

[59] Chung S, Sudo R, Mack PJ, Wan CR, Vickerman V, Kamm RD. Cell migration into scaffolds under co-culture conditions in a microfluidic platform. Lab Chip. 2009;9:26975.

[60] Aizawa Y, Wylie R, Shoichet M. Endothelial Cell Guidance in 3D Patterned Scaffolds. Adv Mater.

[61] Singh M, Morris CP, Ellis RJ, Detamore MS, Berkland C. Microsphere-based seamless scaffolds containing macroscopic gradients of encapsulated factors for tissue engineering. Tissue Eng Part C Methods. 2008;14:299-309.

[62] Wang X, Wenk E, Zhang X, Meinel L, Vunjak-Novakovic G, Kaplan DL. Growth factor gradients via microsphere delivery in biopolymer scaffolds for osteochondral tissue engineering. J Control Release. 2009;134:81-90.

[63] Moore K, MacSween M, Shoichet M. Immobilized concentration gradients of neurotrophic factors guide neurite outgrowth of primary neurons in macroporous scaffolds. Tissue Eng. 2006;12:267-78.

[64] Vepari CP, Kaplan DL. Covalently immobilized enzyme gradients within threedimensional porous scaffolds. Biotechnol Bioeng. 2006;93:1130-7.

[65] Choi K, Kennedy M, Kazarov A, Papadimitriou JC, Keller G. A common precursor for hematopoietic and endothelial cells. Development. 1998;125:725-32.

[66] Iyer RK, Chiu LL, Radisic M. Microfabricated poly(ethylene glycol) templates enable rapid screening of triculture conditions for cardiac tissue engineering. J Biomed Mater Res A. 2009;89:616-31. 
[67] Radisic M, Malda J, Epping E, Geng W, Langer R, Vunjak-Novakovic G. Oxygen gradients correlate with cell density and cell viability in engineered cardiac tissue.

Biotechnol Bioeng. 2006;93:332-43.

[68] Yoshida S, Ono M, Shono T, Izumi H, Ishibashi T, Suzuki H, et al. Involvement of interleukin-8, vascular endothelial growth factor, and basic fibroblast growth factor in tumor necrosis factor alpha-dependent angiogenesis. Mol Cell Biol. 1997;17:4015-23.

[69] Dvorak HF, Brown LF, Detmar M, Dvorak AM. Vascular permeability factor/vascular endothelial growth factor, microvascular hyperpermeability, and angiogenesis. Am J Pathol. 1995;146:1029-39.

[70] Sahni A, Francis CW. Stimulation of endothelial cell proliferation by FGF-2 in the presence of fibrinogen requires alphavbeta3. Blood. 2004;104:3635-41.

[71] Stegmann TJ. FGF-1: a human growth factor in the induction of neoangiogenesis. Expert Opin Investig Drugs. 1998;7:2011-5.

[72] Khurana R, Simons M. Insights from angiogenesis trials using fibroblast growth factor for advanced arteriosclerotic disease. Trends Cardiovasc Med. 2003;13:116-22.

[73] Kutryk MJ, Stewart DJ. Angiogenesis of the heart. Microsc Res Tech. 2003;60:13858.

[74] Chiu LL, Radisic M. Scaffolds with covalently immobilized VEGF and Angiopoietin-1 for vascularization of engineered tissues. Biomaterials. 2010;31:226-41.

[75] Cao X, Shoichet MS. Defining the concentration gradient of nerve growth factor for guided neurite outgrowth. Neuroscience. 2001;103:831-40.

[76] DeLong SA, Gobin AS, West JL. Covalent immobilization of RGDS on hydrogel surfaces to direct cell alignment and migration. J Control Release. 2005;109:139-48.

[77] Chiu LL, Weisel RD, Li RK, Radisic M. Defining conditions for covalent immobilization of angiogenic growth factors onto scaffolds for tissue engineering. $\mathrm{J}$ Tissue Eng Regen Med. 2011;5:69-84. 


\section{Chapter 8 \\ Appendices}

\section{Appendices}

\section{Choice of digestion enzyme}

The collagen scaffold needed to be digested in order to measure the protein content of the scaffold. It was essential to rule out any effects of the digestion enzyme on the protein itself. Hence, several digestion enzymes for collagen were incubated with VEGF overnight. More specifically, $100 \mu \mathrm{l}$ of a $0.6 \mathrm{mg} / \mathrm{ml}$ solution of each of Type II Collagenase (Sigma Aldrich, C6885), Type I Collagenase (Sigma Aldrich, C0130), Type IA Collagenase (C9891), Type II Collagenase (Worthington, CLS-2), dispase (Worthington, NPRO) and PBS was incubated with $100 \mu \mathrm{l}$ of $2 \mu \mathrm{g} / \mathrm{ml}$ VEGF in PBS in a $37{ }^{\circ} \mathrm{C} / 5 \% \mathrm{CO}_{2}$ incubator, bringing the final theoretical concentration to $1 \mu \mathrm{g} / \mathrm{ml}$. The next day, ELISA was performed on the samples to quantify the VEGF content.

Supplemental Figure 1 shows the ELISA readings of the VEGF incubated overnight with several collagen-digesting enzymes. Type IA, Type II from Sigma Aldrich and Dispase did not show significant difference compared to the VEGF Alone control. Based on this, Type IA collagenase was chosen as the digestion enzyme for future studies. 


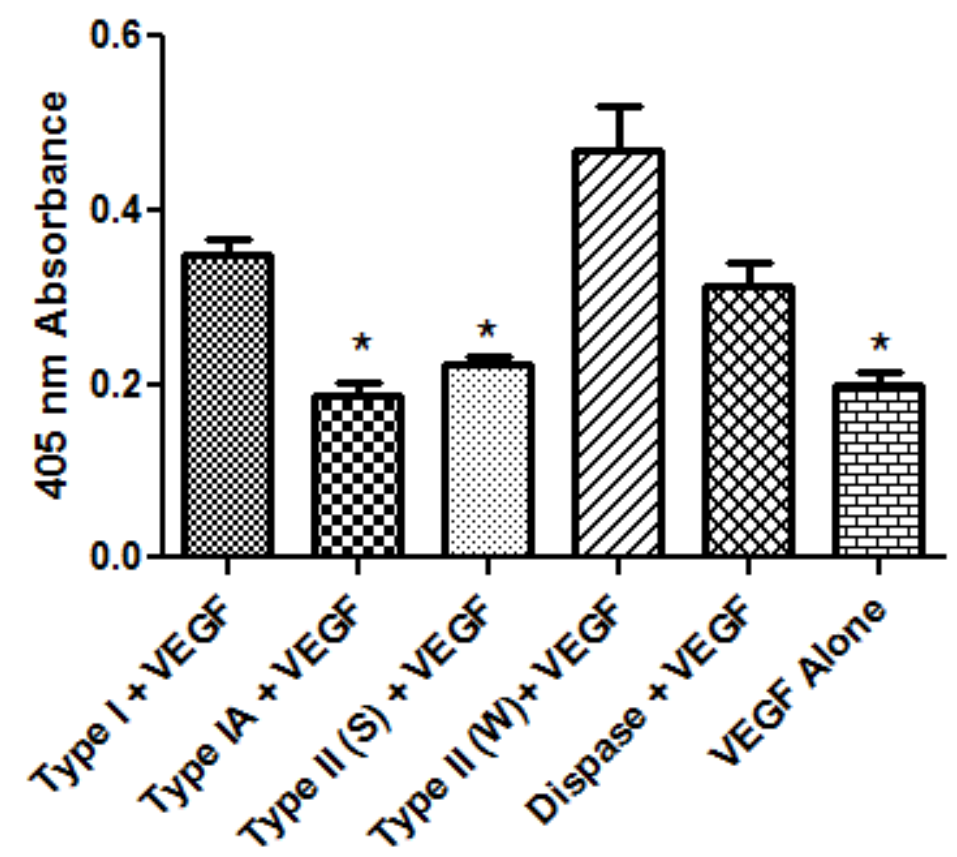

Supplementary Figure 1. Digestion enzyme was selected based on the lowest effect on VEGF detection. VEGF was incubated with various digestion enzymes overnight. It was then quantified using VEGF ELISA kit. Type IA was chosen as the digestion enzyme for further studies since it did not show difference from the VEGF alone control. S: Sigma Aldrich, W; Worthington. Data points with the same symbol indicate groups without statistically significant difference $(p<0.05)$. 

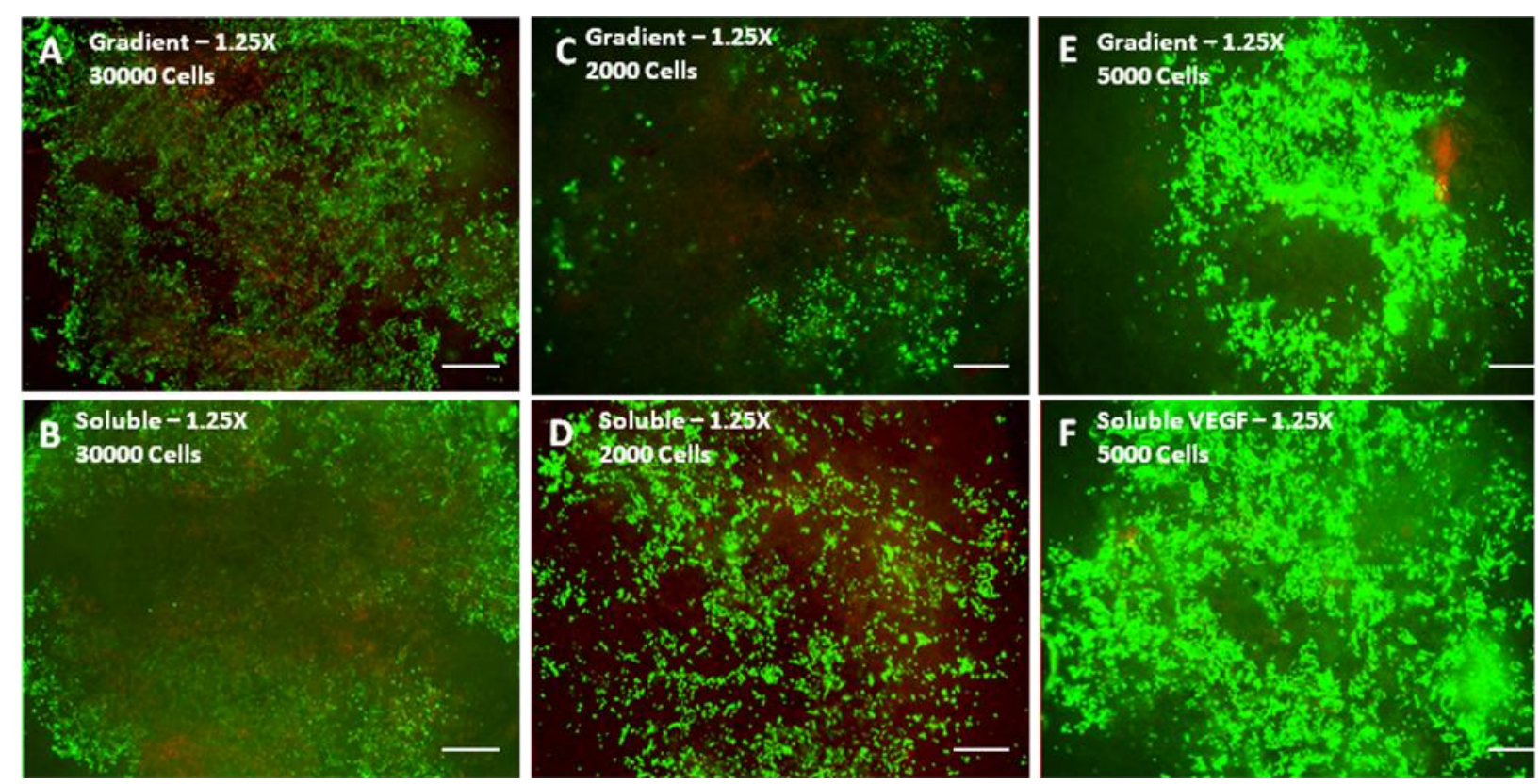

Supplementary Figure 2. Cell density of $\mathbf{5 0 0 0}$ per scaffold was chosen. The scaffolds made with the Point-source method were inoculated with 30,000 (A \& B), 2000 (C \& D) or 5000 (E \& F) cells. One of the samples in the 5000 group showed an effect on the cell distribution, with more cells found near the center of the scaffold (E). Hence, the cell density of 5000 cells was chosen for further cell studies. Scale bar, $750 \mu \mathrm{m}$. 


\section{Cell Seeding Methods}

In every case below, the scaffolds were transferred to a 48 -well plate and stained for Live/Dead using $500 \mu \mathrm{l}$ of the staining solution $(1 \mathrm{~mL}$ PBS $+1.5 \mu \mathrm{l} \mathrm{CFDA}+75 \mu 1 \mathrm{PI})$ per scaffold for 40 minutes in an incubator. They were then washed twice with $1 \mathrm{~mL}$ of PBS and imaged under the microscope under the blue filter. Images were taken at $1.25 \mathrm{X}$.

i. The inoculation method (original method)

Originally the scaffolds were inoculated by spreading the cells over the scaffold in culture medium. More specifically, after the scaffolds have been immobilized and washed, they were transferred to $500 \mu \mathrm{l}$ of culture medium in a 24 well plate in incubator for about 30 minutes. They were then taken out of the incubator, dabbed on autoclaved Kim wipes to remove excess fluid and transferred to a fresh well in a 24-well plate. The desired number of cells $(2000,5000$ or 30,000$)$ were then suspended in $15 \mu$ l of culture medium and spread evenly on the scaffold surface using a $20 \mu 1$ pipette. The scaffolds were placed back into the incubator for 40 minutes for the cells to spread and attach before adding $1 \mathrm{~mL}$ of culture medium.

ii. The orbital shaker method After the immobilization, the scaffold was placed in a well in a $24-w e l l$ plate. The desired number of cells (5000) were then suspended in $500 \mu \mathrm{l}$ of culture medium per scaffold. The medium was then pipetted into the well containing the scaffold and the plate is placed on an orbital shaker in incubator at $37{ }^{\circ} \mathrm{C} / 5 \% \mathrm{CO}_{2}$ on 75 
rpm setting for 1 hour. The culture medium was then aspirated and fresh medium was supplemented.

iii. The centrifugation method The same method as in (b) was followed, except that the plate containing the scaffolds was centrifuged in a plate centrifuge at $1000 \mathrm{rpm}$ for 5 minutes at $4{ }^{\circ} \mathrm{C}$. This caused the cells to deposit on the scaffold evenly. The scaffolds were then transferred to new wells.

iv. The rotator method

The immobilized scaffolds were suspended in a $15 \mathrm{~mL}$ tube containing $10 \mathrm{~mL}$ of culture medium with the desired number of cells $(25,000$ or 50,000$)$. The tube was mounted on a vertical rotator and rotated at 3.5 setting for 1 hour at room temperature. The scaffolds were then transferred to plates. 

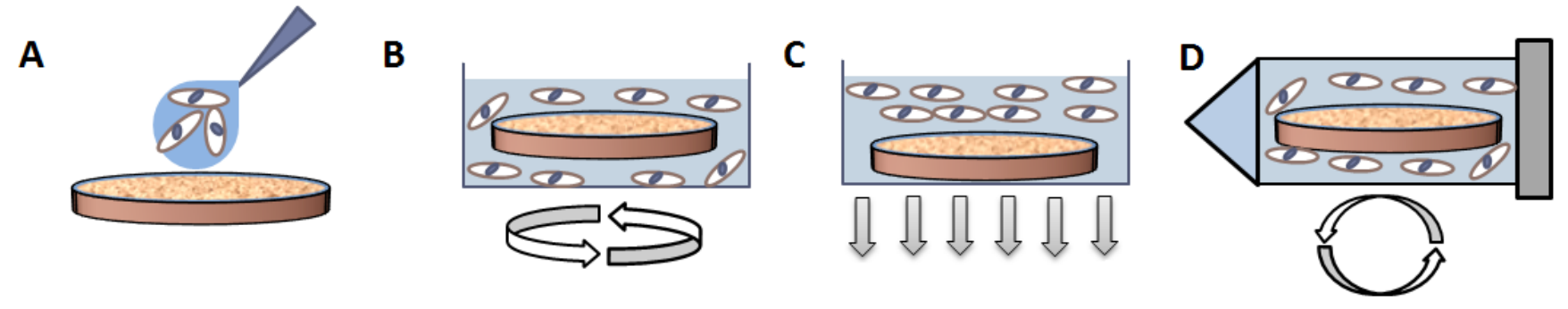

Supplementary Figure 3. Overview of the Cell Seeding Methods. (A) The inoculation method. Cells were suspended in $10 \mu \mathrm{l}$ of culture medium and inoculated evenly on the scaffold. (B) The orbital shaker method. The scaffold was placed in a cell suspension on orbital shaker at $75 \mathrm{rpm}$ for 1 hour. (C) The centrifugation method. The scaffold was placed in a cell suspension and the cells were spun down at $1000 \mathrm{rpm}$ for 5 minutes on the scaffold. (D) The rotator method. The scaffold was placed in a cell suspension in a $15 \mathrm{~mL}$ tube and rotated in a circular fashion at 3.5 setting for 1 hour.

The cell distribution for each method is given in Supplementary Figure 4. All of the methods lead to cell attachment on the scaffold. However, the centrifugation method seems to lead to the most even distribution of the cells. Another advantage of using this method was that it is fast (centrifugation takes only 5 minutes), hence minimizing the time cells spend in non-ideal conditions. 

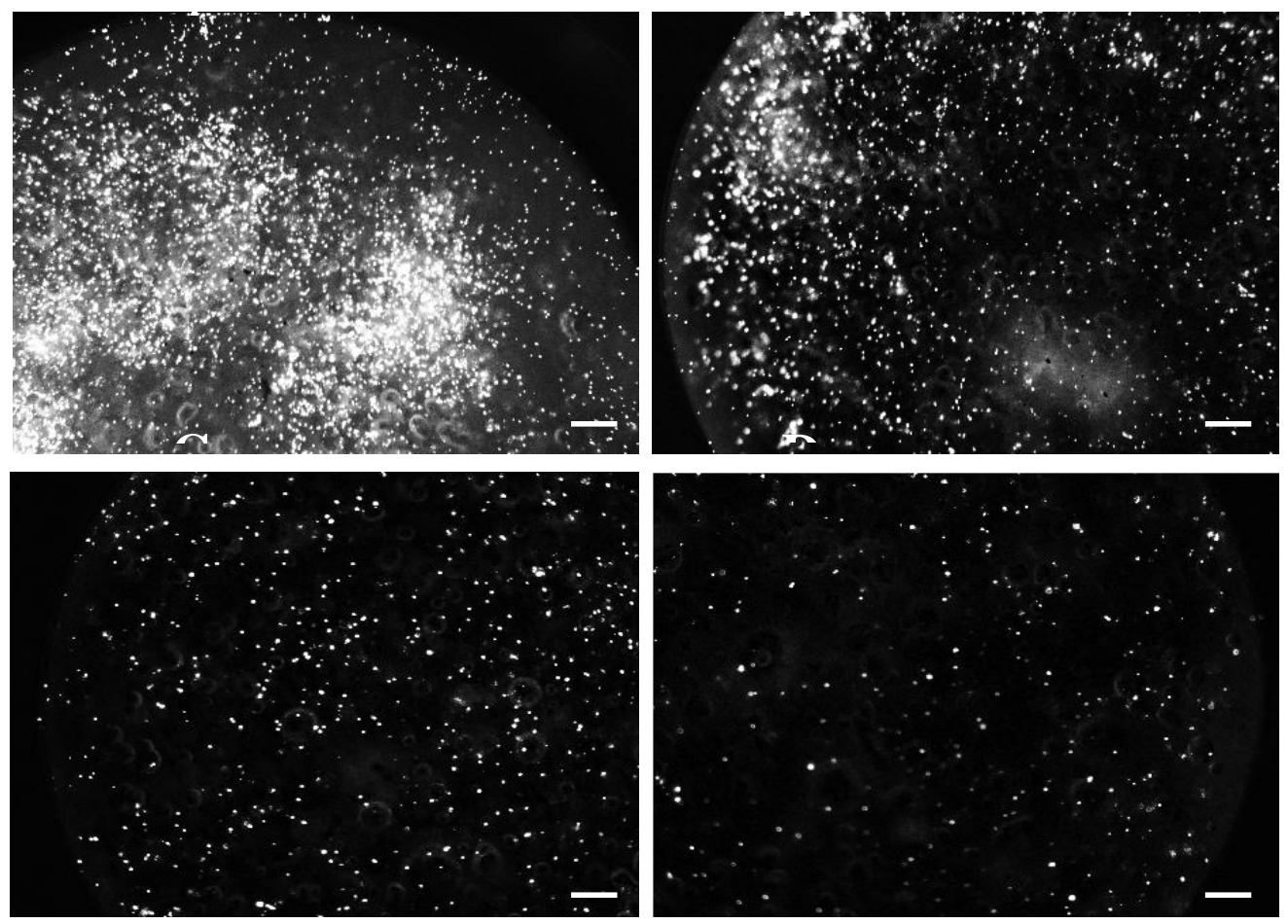

Supplementary Figure 4. Cell distribution varied for different seeding methods. (A)

The inoculation method. This method results in uneven distribution of the cells as observed by the patches. (B) The orbital shaker method. This results in uneven distribution with more cells accumulating at the peripheries. (C) The centrifugation method. This results in a relatively uniform distribution of the cells. (D) The rotator method. This results in very small number of cell seeding. The centrifugation method was chosen for further cell studies. Scale bar, $500 \mu \mathrm{m}$. 